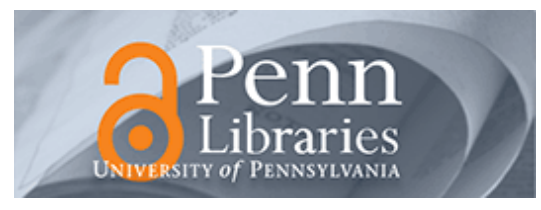

University of Pennsylvania

ScholarlyCommons

$10-2010$

\title{
You Can Take It with You: Proposition 13 Tax Benefits, Residential Mobility, and Willingness to Pay for Housing Amenities
}

Fernando V. Ferreira

University of Pennsylvania

Follow this and additional works at: https://repository.upenn.edu/bepp_papers

Part of the Business Commons, Economics Commons, and the Public Affairs, Public Policy and Public Administration Commons

\section{Recommended Citation}

Ferreira, F. V. (2010). You Can Take It with You: Proposition 13 Tax Benefits, Residential Mobility, and Willingness to Pay for Housing Amenities. Journal of Public Economics, 94 (9-10), 661-673. http://dx.doi.org/10.1016/j.jpubeco.2010.04.003

This paper is posted at ScholarlyCommons. https://repository.upenn.edu/bepp_papers/30

For more information, please contact repository@pobox.upenn.edu. 


\title{
You Can Take It with You: Proposition 13 Tax Benefits, Residential Mobility, and Willingness to Pay for Housing Amenities
}

\begin{abstract}
The endogeneity of prices has long been recognized as the main identification problem in the estimation of marginal willingness to pay (MWTP) for the characteristics of a given product. This issue is particularly important in the housing market, since a number of housing and neighborhood features are unobserved by the econometrician. This paper proposes the use of a well defined type of transaction costs-moving costs generated by property tax laws-to deal with this type of omitted variable bias. California's Proposition 13 property tax law is the source of variation in transaction costs used in the empirical analysis. Beyond its fiscal consequences, Proposition 13 created a lock-in effect on housing choice because of the implicit tax break enjoyed by homeowners living in the same house for a long time. Its importance to homeowners is estimated from a natural experiment created by two amendments that allow households headed by an individual over the age of 55 to transfer the implicit tax benefit to a new home. Indeed, 55-year old homeowners have $25 \%$ higher moving rates than those of comparable 54 year olds. These transaction costs from the property tax laws are then incorporated into a household sorting model. The key insight is that because of the property tax laws, different potential buyers may have different user costs for the same house. The exogenous property tax component of this user cost is then used as an instrumental variable. I find that MWTP estimates for housing characteristics are approximately $100 \%$ upward biased when the choice model does not account for the price endogeneity.
\end{abstract}

\section{Keywords}

housing demand, transaction costs, household behavior

\section{Disciplines}

Business | Economics | Public Affairs, Public Policy and Public Administration 
CENTER FOR LABOR ECONOMICS

UNIVERSITY OF CALIFORNIA, BERKELEY

WORKING PAPER NO. 72

\title{
You Can Take It with You: \\ Transferability of Proposition 13 Tax Benefits, Residential Mobility, and Willingness to Pay for Housing Amenities
}

\author{
Fernando Vendramel Ferreira* \\ University of California, Berkeley
}

June 2004

\begin{abstract}
In 1978, Californians approved Proposition 13, which fixed property tax rates at 1\% of housing prices at the time of purchase. Beyond its fiscal consequences, Proposition 13 created a lock-in effect on housing choice because of the implicit tax break enjoyed by homeowners living in the same house for a long time. In this paper, I provide estimates of this lock-in effect, using a natural experiment created by two subsequent amendments to Proposition 13 - Propositions 60 and 90. These amendments allow households headed by an individual over the age of 55 to transfer the implicit tax benefit to a new home. I show that mobility rates of 55-year old homeowners are approximately $25 \%$ higher than those of 54 year olds. The second contribution of this paper is the incorporation of transaction costs, due to Proposition 13, into a household location decision model, providing a new way to estimate marginal willingness to pay (MWTP) for housing characteristics. The key insight of this model is that because of the property tax laws, different potential buyers have different user costs for the same house. The exogenous property tax component of this user cost then works as an instrument to solve the main identification problem of revealed preference models - the correlation between price and unobserved quality of the product.

\footnotetext{
* I am grateful to David Card and Kenneth Chay for their invaluable guidance and support. I also would like to thank Patrick Bayer, Tom Davidoff, David Lee, Robert McMillan, Edward Miguel, Aviv Nevo, John Quigley, Steven Raphael, Kim Rueben, Emmanuel Saez, and participants in the UC Berkeley Labor Seminar and UC Berkeley Real Estate Seminar for providing many comments and suggestions. This research was partially conducted at the California Census Research Data Center; my thanks to the CCRDC, especially to Henry Brady, Andrew Hildreth and Ritch Milby. I gratefully acknowledge the financial support for this dissertation provided by the CAPES-Brazil, CCRDC, IBER-UC Berkeley and UC Berkeley Graduate Division.
} 


\section{Introduction}

Household sorting in the urban housing market has attracted the attention of economists since the pioneering work of Tiebout (1956). ${ }^{1}$ Empirical research on local public finance, school choice, and segregation patterns, for example, generally apply equilibrium sorting concepts originated in this literature. ${ }^{2}$ In spite of its elegance, however, some of the Tiebout assumptions may not be credible, such as the free mobility of households. ${ }^{3}$ In reality, transaction costs and other barriers to sorting systematically affect individual behavior, although it is a difficult task to precisely measure those costs. ${ }^{4}$

In this paper I study the impact of one type of transaction costs - moving costs generated by property tax laws - on household mobility and how it can be used to recover preference parameters in a residential sorting model. The key insight is that in states where property taxes are based on historical prices rather than current market values, potential house buyers have different user costs for the same property. This research focuses on housing demand in California, where Proposition 13, passed in 1978, created unusually wide variation in property tax rates. ${ }^{5}$

\footnotetext{
${ }^{1}$ Much of the intuition on household sorting was derived from a long line of theoretical work in local public finance that started in Tiebout (1956), and which includes Epple and Zelenitz (1981), Epple, Filimon, and Romer (1984, 1993), Benabou (1993), Nechyba (1997) and Epple and Sieg (1999).

2 Recent examples are found in Barrow and Rouse (2000), Rothstein (2003) and Bayer, McMillan and Rueben (2002).

3 As Rubinfeld (1987) points out "the value and usefulness of the Tiebout model is likely to diminish in the future, and an alternative or alternatives are needed."

${ }^{4}$ See Quigley (2001) for a survey on the different types of transaction costs.

5 The passage of Proposition 13 in 1978 was the most important public finance event in recent California history. Its effects still reverberate today, as recurrent state budget pressures lead to under funding of education and other essential public services. Several papers, such as Shapiro and Sonstelie (1982a), Shapiro and Sonstelie (1982b), Fischel (1989), Silva and Sonstelie (1995) and Brunner and Rueben (2001) study the fiscal consequences of Proposition 13. More recently, the news media focused its attention in the California budget crisis. For example, Paul Krugman in his New York Times editorial of 08/22/2003 wrote "What is true [about the budget crisis] is that California's taxes are highly inequitable: thanks to Proposition 13, some people pay ridiculously low property taxes.
} 
Proposition 13 replaced a decentralized system of property tax rates around 2-3\% of assessed house values, with a uniform $1 \%$ fixed rate, based on prices at the time of purchase. The immediate effect of Proposition 13 was a one-time reduction in local property tax revenues. ${ }^{6}$ The longer-run impact was to create a system of "grand-fathered" tax rates for houses based on historical prices. The associated tax savings can be substantial: Considering the one quarter of San Francisco Bay Area families with more than 20 years of housing tenure in 1990, I estimate that these savings amounted to an average of $4.5 \%$ of household gross annual income. The grand-fathering of tax rates therefore creates a "lock-in" effect, since a homeowner who moves to another home may experience a large increase in tax liability. ${ }^{8}$

However, under a pair of propositions passed in the late 1980's (Proposition 60 in 1986, and Proposition 90 in 1988), homeowners aged 55 or older who sell a property and buy another of equal or lesser value are allowed to keep the tax base value of their original home. These laws created a sharp discontinuity in the lock-in effect of Proposition 13, giving rise to an interesting natural experiment for estimating the impact of moving costs on mobility.

The first goal of this paper is to estimate the lock-in effect attributable to Proposition 13 by comparing householders who are 54 years old to those who are $55 .^{9}$ I find that 55 -year olds

\footnotetext{
Warren Buffett offered the perfect example: he pays $\$ 14,401$ in property taxes on his $\$ 500,000$ home in Omaha, but only $\$ 2,264$ on his $\$ 4$ million home in Orange County."

6 Total property tax revenues in California declined by $45 \%$ in $1978-1979$. Also, the share of local counties ${ }^{`}$ revenue from property taxes declined from 33\% in 1977-1978 to 11.6\% in 1995-1996 - see Silva and Sonstelie (1995).

7 In California the implicit tax benefit reached 3\% of the gross income for the same selected group of households. These calculations are explained in Section 3.

8 This type of effect is analogous to the spatial lock-in related to falling housing prices, as in Caplin, Freeman and Tracy (1997) and Chan (2001), or due to increase in interest rates, as in Quigley (1987). Other types of lock-in occur on capital gain taxation, see Auerbach (1992), wages, see Akerlof, Rose and Yellen (1990), and job-lock due to health insurance, see Madrian (1994).

${ }^{9}$ Few papers look at the effects of Proposition 13 on mobility. Sexton, Sheffrin and O'Sullivan (1995, 1995a) use a simulation model to compute how mobility changes in a switch to an acquisition-value tax. Sexton, Sheffrin and O'Sullivan (1999) report descriptive statistics with the individuals most benefited by the tax discount due to increase in prices. Nagy (1997) looks at mobility rates before and after the law approval, finding no significant effects (the lock-in effect could only have an impact after a significant house prices increase). Rosen (1982) looks at the way interjurisdicion capitalization changed after Proposition 13. He found that each dollar decrease in relative property taxes led to a seven dollar increase in house values, provided no reduction in local public services.
} 
have a 1.2-1.5 percentage point higher rate of moving (on a base of approximately 4\%). Consistent with a tax-based explanation for this difference, 55 -year old recent movers paid 15\% less property taxes than their 54-year old counterparts. To check whether this change in mobility is due to other discontinuous trends, I look at mobility rates for various control groups, including California homeowners in 1980 and renters in 1990, and Texas homeowners in 1990. In all, I find no evidence of a discontinuity. Moreover, there are no differences in property taxes paid by 54 and 55 -year old recent movers for these control groups.

The second goal of this study is to explicitly incorporate transaction costs due to Proposition 13 in a household location decision model. The output from this revealed preference model consists of a set of underlying taste parameters for housing and neighborhood characteristics, which are of special interest for understanding sorting patterns and valuation of local public amenities. Here I adopt estimation strategies first used by McFadden (1974 and 1978), and recently updated by Berry (1994) and Berry, Levinsohn and Pakes (1995). ${ }^{10}$

There are two main differences between my method and other revealed preference models. First, I create a user cost of the house that is specific to each homeowner, representing a combination of prices and property taxes. Second, I use the variation in moving costs created by Proposition 13 as an instrument to control for the correlation between price and the unobserved housing quality. ${ }^{11}$

The implementation of this sorting model is only feasible using the 1990 California Decennial Census Long Form data, which is a 15\% sample. These are restricted-access micro

\footnotetext{
${ }^{10}$ For a detailed explanation of the random coefficients multinomial logit model, see Nevo (2000). A review of the earlier literature can be found in Train (2000).

${ }^{11}$ It is very hard to find credible instruments to control for the correlation between prices and unobserved housing quality in the literature. Bajari and Kahn (2001) estimate bounds on willingness to pay for distance to work in order to avoid the use of instruments. Bayer, Ferreira and McMillan (2003) instrument price with a quasi optimal instrument derived from the choice model and from land use measures, to estimate valuation of school quality. In the automobile case, Berry, Levinsohn and Pakes (1995) use functions of cost and demand characteristics of all products in a given year as instruments, where the functions are defined as optimal instruments using polynomial approximations.
} 
data, with information for approximately two million households in California, including the property taxes paid by each. Unlike the publicly available micro sample, in which the smallest geographic area contains 100,000 individuals, the 15\% sample reveals the location of each house and work place at the Census block level, a region with approximately 100 individuals. This special feature allows me to precisely define neighborhoods, and at the same time incorporate a rich set of observed heterogeneity, such as income, race, age and distance to work.

Simple multinomial logit estimates of the sorting model generate a relatively small user cost coefficient, indicating very high preferences for certain housing characteristics. This result is typical of an omitted variable bias situation: given that we do not observe all housing amenities, prices tend to be higher for houses with valuable unobserved attributes. This problem can be solved by including a control function, in which differences in the tax cost across houses attributable to Proposition 13 work as an instrumental variable for the user cost. ${ }^{12}$

Preference parameter estimates from the adjusted model are then used to recover estimates of the marginal willingness to pay (MWTP) for housing and neighborhood attributes. I find that homeowners are willing to pay, on average, annually $\$ 1,900$ for one extra room, $\$ 4,100$ for a detached house (compared to other housing types), and $\$ 1,300$ to live in a neighborhood with $\$ 10,000$ higher average income. These results hold after the inclusion of heterogeneity and wealth effects. Interestingly, the same estimation method breaks down when applied to Texas, given the lack of meaningful variation in property taxes for that state.

The rest of this paper is organized as follows. Section 2 explains Proposition 13 in detail. Section 3 describes the data set, and provides descriptive statistics to analyze the beneficiaries of Proposition 13. Section 4 estimates the lock-in effect. Section 5 presents a household residential location model, and estimates of MWTP for housing characteristics. Section 6 concludes.

12 Section 5.4 provides specification tests for the instruments and a detailed investigation of the sources of identification of the sorting model. 


\section{Proposition 13}

Proposition 13 was approved in 1978 by 65\% of the voters in California. The vote was widely interpreted as a "tax revolt" against the state government. ${ }^{13}$ In the mid-1970's, property $\operatorname{tax}$ revenues in California were quickly fueled by sky-rocketing house prices and the unwillingness of local officials to cut property tax rates in the face of a growing tax base. Advocates of the proposition argued that tax increases were forcing elderly and low-income families to sell their homes. At the same time, school spending the state was dramatically changing in response to the California Supreme Court's decision, Serrano vs Priest (1971), which required the equalization of spending per pupil across school districts. Fischel (1985) argues that the cost of the equalization program provoked a reaction by the voters in the form of restricting government revenues through Proposition 13.

Proposition 13 states that "the maximum amount of any ad valorem tax on real property shall not exceed one percent (1\%) of the full cash value of such property"14. Full cash value means price at the time of purchase plus a maximum inflation adjustment of 2 percent per year. No re-assessment could be carried out, implying that property taxes are effectively frozen (apart from the $2 \%$ per year rise). ${ }^{15}$

The law had two other important sections. First, although property taxes were fixed at $1 \%$ for all local governances, this limitation would not apply to additional taxes to pay for bonds

\footnotetext{
13 In the "Howard Jarvis Taxpayers Association: dedicated to protecting Proposition 13 and promoting taxpayers" rights" website, for example, we can find citations like "Proposition 13 has reached the exalted status of a symbol for taxpayer revolt and people controlling the power of their government".

${ }^{14}$ California Constitution, Article XIIIa.

15 "The full cash value base may reflect from year to year the inflationary rate not to exceed 2 percent for any given year or reduction as shown in the consumer price index or comparable data for the area under taxing jurisdiction, or may be reduced to reflect substantial damage, destruction or other factors causing a decline in value." California Constitution, Article XIIIa. It is interesting to note that the initial base values used to set property taxes were the assessed housing values of 1975/1976.
} 
approved by voters before 1978, and beginning in 1984 for new bonds approved by a supermajority of voter. ${ }^{16}$ Second, Proposition 13 required that any new taxes proposed by the state legislature had to be approved by a two-thirds majority of each house. ${ }^{17,18}$

Two important modifications to Proposition 13 were enacted during the next decade. Proposition 60 was a constitutional amendment approved in 1986, which allowed the transfer of tax benefits for within-county movers. Proposition 60 permits a transfer of a Proposition 13 base year value of the property from the current residence to a replacement dwelling if: a) homeowners are at least 55 years old; and b) the replacement dwelling is of equal or lesser value than the selling price of the old property. In practice, Proposition 60 enabled 55-year or older households to carry the frozen property taxes to a new home within the same county. ${ }^{19}$

Proposition 90, approved in 1988, brought even more flexibility, allowing inter-county base year value transfers. Adoption of Proposition 90 was not mandatory and the law only applies across counties that approved the ordinance. Only a few, albeit relatively large, counties in California adopted Proposition 90 immediately after approval of the law, namely: Alameda, Contra Costa, Inyo, Kern, Los Angeles, Marin, Modoc, Monterrey, Orange, Riverside, San Diego, San Mateo, Santa Clara, and Ventura. ${ }^{20}$

\footnotetext{
${ }^{16}$ Other local taxes and fees have increasingly required voter approval - see Rueben and Cerdan (2003).

17 California Constitution Article XIIIa.

18 Other interesting details of the law are: ability to transfer the tax benefit to a spouse or children, exemption for disabled households and exemption for $\$ 7,000$ of the house value when occupied by an owner as his principal residence. Also, owners are allowed to use real estate taxes as itemized deductions on Federal income taxes.

19 Although anecdotal evidence indicates that Proposition 60 was approved because of the pressure made by the same Proposition 13 voters, the rationale of this law according to the Legislative Analyst's Office website is that “...it removes a disincentive for senior citizens who no longer need family-sized dwellings or dwellings located near schools or places of employment to move to more suitable homes, thereby increasing the availability of suitable housing for younger families."

${ }^{20} 60 \%$ of the state population is located in these counties. Four of those counties have subsequently repealed the ordinance: Contra Costa, Inyo, Marin and Riverside.
} 


\section{Data set}

The Integrated Public Use Microdata Series (IPUMS) 5\% samples of the 1980 and 1990 for the states of California and Texas are the main source of data for this paper. I also use the California Decennial Census Long Form data, a 15\% sample, to estimate the model developed in section $5 .{ }^{21}$ In addition to containing precise location information, the Long Form database also includes more complete data on key variables, such as property taxes. In particular, although the public use files of the Census top code property taxes at $\$ 5,000$ and report only discrete ranges of taxes, the restricted Long Form data have the exact property tax paid by all households up to a $\$ 15,000$ cap.

Table 1 shows a summary of the main Census variables for California and Texas in 1980 and 1990. Column (1) shows averages of house values, property taxes, effective tax rates (individual house values divided by property taxes), house and household characteristics for the full sample. Columns (2)-(7) have the same averages for different subgroups, by date when they moved into their home. The choice of Texas as comparison group comes from the fact that house values are re-assessed every two to three years in that state.

A striking feature of these data is the gap in effective property taxes paid by homeowners of different tenures in California in 1990. While homeowners who had moved in the previous year paid an effective tax rate of $0.8 \%$ on average, households living in the same dwelling for more than a decade paid less than $0.44 \%$. This discrepancy corresponds to a tax saving of $\$ 900$ per year in 1990 dollars. If we focus on the implicit tax benefit - the difference between current property taxes and 1\% of house values - for households who moved in before 1979, this number can reach almost 3\% of household gross annual income. In some places, such as the San

${ }^{21}$ Only part of the analysis is conducted with the $15 \%$ sample because of delays in getting access to the restricted data. 
Francisco Bay Area, the implicit tax benefit reached almost $4.5 \%$ of gross income for the same selected group of households.

When looking at California in 1980, by comparison, we only see a small difference in effective property taxes between homeowners who moved before 1975 and those who moved after. $^{22}$ This is the initial consequence of Proposition 13 , when property taxes were set at $1 \%$ of house values assessed in 1975. As opposed to California, the Texas data show relatively stable effective property tax rates. Only households who moved before 1970 have discounts in property taxes, presumably because Texas offers special deductions for householders 65 years of age and older.

Interestingly, we do not observe differences across tenure groups or the number of rooms in California in 1990. Other housing amenities, such as housing type and year of construction, have a strong tenure gradient. As expected, we also observe an "age" gradient, given that tenure is correlated with age. Also, long tenure homeowners are more likely to have lower income and lower education than others. The same trends are observed in Texas, although house values are slightly positively correlated with age of the units in Texas.

Figure 1 plots effective property tax rates by age for California homeowners in 1990. The distributional effects of Proposition 13 are clear: elderly (long tenure) households pay less property tax than younger (recent movers) households. When normalizing property taxes by annual household income instead of house values (Figure 2) the distributional effects of Proposition 13 are less pronounced. The main characteristic is that individuals between 50-60 years of age pay less tax as a proportion of their income compared to other age groups. This might reflect the age profile of income, where maximum income is generally achieved around

\footnotetext{
${ }^{22}$ Half of the 1980 sample was not included because the Census did not process the mobility information for a random sample of half of the population. This scheme was applied to reduce costs of processing the information from mobility variables.
} 
age 50. In comparing current taxes with a counterfactual $1 \%$ of housing values as property taxes, the gap between what Californians should pay in a different regime is much larger for the elderly. The same pattern of implicit tax benefits is observed for low-income householders, as plotted in Figure 3.

\section{Lock-in Effect}

The lock-in effect of Proposition 13 arises because of the implicit tax break for households who have been living in the same house for a long time. To the best of my knowledge, there is no formal analysis of the magnitude of the lock-in effect in the literature. This paper is the first research to identify the lock-in, by looking after age 55, when the lock-in effect is removed.

Figure 4 illustrates the key insight of the new research design. It graphs the probability of moving to a new house in 1990 by age group. Each dot in Figure 4 is calculated as the total number of homeowners who moved in the last year, divided by the total number of homeowners from the respective age. From now on, age is defined as the maximum age between householder and spouse, to correspond with the provisions of Propositions 60 and 90.

A sharp discontinuity arises between 54 and 55-year olds. The probability of moving for a 54 -year old is $4 \%$ while for 55 year olds it reaches $5.2 \%$. This $1.2 \%$ point difference is presumably caused by the effect of Propositions 60 and 90 . The remainder of this section presents a variety of tests of this interpretation.

In order to rule out competing hypothesis, I compare 1990 California data with several control groups, such as California data from 1980, before Propositions 60 and 90 had been 
approved. Figure 5 graphs the probability of moving for this group, where only the negative relationship between mobility and age is found. This comparison rules out any type of special Californian mobility pattern as the explanation for the sharp change in mobility rates.

Figure 6 plots the probability of moving for renters in California 1990. Again, no discontinuity is found for the relevant age group. The existence of a 1989-1990 localized year effect is ruled out by this comparison. Figure 7 plots the probability of moving for homeowners in Texas in 1990. Again, no discontinuity is found, allowing me to rule out national economic shocks or trends as cause of the change in mobility rates for 55-years old in California in 1990.

Table 2 reports results from a probit model, designed to quantify the patterns observed in the figures above. The following reduced form equation for the probability of moving in 1990 is estimated:

$$
\operatorname{Pr}(\text { moving })_{i}=\Phi\left(\delta_{1} D_{i}^{55}+\delta_{2} A g e_{i}+\delta_{3} A g e_{i}^{2}+\delta_{4} A g e_{i}^{3}\right)
$$

where $D_{i}^{55}$ is a dummy for 55 -year or older and $\Phi($.$) is the normal c.d.f.. The extra age controls$ are included in the equation because the effect of age on mobility is non-linear. Column (1) shows a negative correlation between $D_{i}^{55}$ and the probability of moving, due to the negative impact of age on mobility rates. Column (3) adds the polynomial in age, leading to a change in the sign of the age 55 and older dummy, and setting the effect of $D_{i}^{55}$ on mobility in $1.5 \%$ points (with t-stat 5.2). This result is unchanged with the addition of house attributes, household characteristics or fixed effects at the metropolitan area. Pooling the 1990 California data with 1980 California data or the 1990 Texas data increases the estimated effect to $1.7 \%$ and $2 \%$ respectively, which is consistent with the downward trend in mobility rates observed in 
those control groups.

Two other consistency checks are presented in Table 2. First, I exclude 54 to 55-year households from the sample. This test verifies the existence of a structural change in mobility rates as opposed to only 54-years homeowners delaying mobility until they are 55 years old. Again, results are very similar to the initial estimates. Finally, I estimate the mean marginal effect of age instead of the marginal effect at the mean, finding a $1.7 \%$ change in mobility rates.

It is important to note that the reduced form results hold for the full local population of 54 and 55-year old, independent of their moving status. Given the 1-year difference in both cohorts, there is no reason to expect differences in preferences or average characteristics of those households. Table 3 reports average values for relevant characteristics for 52-57-year old homeowners. A smooth trend is the main characteristic in most variables, without any sharp discontinuity between 54 and 55-year olds, as expected. All the comparisons above point out to a causal relationship between the ability to transfer the tax benefit and mobility rates. ${ }^{23}$

\subsection{Consistency checks}

The main consistency check relates to the ability of transferring the tax benefit. If recent movers in fact used Propositions 60 and 90, a discontinuity in property taxes payments would be expected. Figure 8 shows average property taxes by age. The gap between 54 and 55 year olds is approximately $\$ 200$, and is only noticeable in California in 1990. Figure 9 and Figure 10 show the same numbers for California in 1980 and Texas in 1990. In both cases, only a downward trend in property taxes payments is observed, especially for Texas, where 65 year of age or older

\footnotetext{
${ }^{23}$ A remaining question relates to how permanent or transitory are the effects of Propositions 60 and 90 . Given that we are looking at mobility rates in 1989-1990, 3 years after Proposition 60's approval and 1 year after Proposition 90, potentially these analyses capture mobility for a stock of households that were mismatched for some period of time. The Census 2000 would be ideal to confirm the change in mobility patterns. Unfortunately, the Census 2000 has extremely high allocation rates. For example, almost 50\% of house values were not reported. The high non-response rates generated counterintuitive mobility rates of 8-9 percentage points for the 54-55-year old homeowners, departing from a pattern of reduction in mobility rates over time.
} 
households enjoy several deductions in their tax payments. Figures 11, 12 and 13 compare effective property tax rates faced by new movers in California 1990, California 1980 and Texas 1990 respectively. Again, the discontinuity is only present in the 1990 California data. Table 4 shows estimates of this difference, which is of $0.08 \%$ (compared to an average tax rate of $0.8 \%$ for all recent movers).

The $\$ 200$ gap in taxes between 54 and 55 year old Californians in 1990 seems a small number compared to the differences in property tax payments reported in Table 1. If long tenure households were moving in 1989-1990 in similar proportions, i.e., "when moved in" groups were contributing with proportional number of recent movers, the expected average gap would be $\$ 536$. This indicates that long tenure homeowners were probably moving with lower rates than short tenure homeowners. Also, 55-year old homeowners moving to more expensive houses are not allowed to transfer the tax benefit.

A second explanation for the small gap is that counties in California take 6 to 7 months to actually transfer the tax benefit. Once a family moves to a new place, the householder has to visit the county office and request the transfer of base values. After the request is accepted, it takes 6-7 months for the approval process. Meanwhile, households pay higher tax rates, only receiving the re-fund in the next payment. Given that most households filled the Census questionnaire in the beginning of 1990, we should expect to see a fair proportion of households reporting higher property taxes than they actually have to pay. ${ }^{24}$

Families moving to counties that did not allow Proposition 90 are a third explanation for the modest tax difference. Figure 13 shows the probability of moving for California 1990 split in two groups: movers who could transfer the tax benefit (because of Proposition 60 or 90) and movers who could not (because Proposition 90 was not allowed). The comparison is made

\footnotetext{
24 The 1990 Census question for property taxes was: “What were the real estate taxes on THIS property last year?”
} 
using the Census question: "Where did this person live 5 years ago (on April 1, 1985)?" 22\% of the 54 and 55-year olds recent homeowners moved to places that did not accept Proposition 90. Figure 14 also allows me to calculate the discontinuity in both groups. Only the group allowed to transfer the tax benefit had a gap of $.95 \%$ points between probabilities of moving for 54 and 55 years old. The same comparison is made in Figure 15, but plotting average property taxes instead of mobility rates. Not surprisingly, the gap between 54 and 55-year old increased to $\$ 300$ when comparing the predicted average property taxes.

A final explanation for the $\$ 200$ gap instead of $\$ 536$ is that some of the new movers may have been renters in the previous house. Although I am not able to verify it in the Census data, there are two indications that this number is significant. First, the proportion of 54-55 years old non-movers who are renters is $20 \%$ for California in 1990. Also, the March CPS started to collect answers to the question "What was (your/name) main reason for moving?" in 1998. Table 5 has the frequency of answers by age groups for the whole US. Only $16.2 \%$ of the 50-59 years of age households pointed out "wanted to own home, not rent" as the main reason to move. This proportion is larger for younger cohorts, as younger families buy their first house.

Older cohorts, on the other hand, are more likely to move after retirement and less likely to move because of change in marital status. Interestingly, the main reason for moving is due to housing and neighborhood quality. This provides extra incentive for calculating MWTP for housing and neighborhood characteristics in Section 5, when the variation in moving costs is used an instrument to control for the correlation between price and unobserved quality of the neighborhood. 


\section{Residential Location Decisions Model}

In this section I develop a household residential demand model, ${ }^{25}$ where the focus is on the incorporation of transaction costs represented by Proposition 13. Taxation costs are included into the model and used as a device to recover estimates of the marginal willingness to pay (MWTP) estimates for housing and neighborhood attributes. The key insight of the model is the construction of a user cost for a house that varies across people. The property tax differences created by Proposition 13 provides exogenous variation in user costs, and can be used as an instrumental variable to reduce the influence of unobserved house characteristics in estimating MWTP. ${ }^{26}$

The model is based on standard differentiated product demand models, whose roots lie in the work of McFadden $(1973,1978)$ and more recently Berry (1994) and Berry, Levinsohn and Pakes - BLP (1995). The central idea is that demand parameters can be recovered from observed choices in the housing market, where houses are considered as bundles of characteristics. Households choose to live in the house that maximizes expected utility derived from housing and location attributes.

A number of existing studies have used similar or related frameworks to estimate preferences for housing and neighborhood characteristics. Palmquist (1984) directly estimated demand for certain house characteristics in seven metropolitan areas using the hedonic approach developed by Rosen (1974). ${ }^{27}$ Quigley (1985) applied a discrete choice model to recover

25 The supply side is not modeled in this paper. The housing supply is assumed to be fixed in all estimates.

${ }^{26}$ To implement this identification strategy, a control function technique is used. Hausman (1978), Heckman (1978) and Smith and Blundell (1986) initially developed the method, and it can be thought as a two-stage least square approach applied to non-linear models. Blundell and Powell (2001) expanded the control function ideas in a semi-parametric and non-parametric estimation. Applications of the control function are found in Villas-Boas and Winer (1999) and Petrin and Train (2002).

27 Sheppard (1997) provides an overview of the problems associated with hedonics analysis of housing markets and the empirical problems associated with this branch of the literature. 
preferences for housing and neighborhood attributes in Pittsburgh. Recently, several papers adapted the BLP approach to the housing market, including Bajari and Kahn (2000), Bayer, McMillan and Rueben (2003) and Bayer, Ferreira and McMillan (2003). These last two papers also develop an equilibrium model of the housing market, allowing the estimation of general equilibrium simulations to evaluate changes in policy. None of these papers, however, explicitly takes into account the variation in user costs of alternative housing units posed by Proposition 13 or similar laws in other states.

\subsection{The model}

Assume that household $i$ maximizes utility by choosing among alternative houses indexed by $j$. The indirect utility of household $i$ from consuming house $j$, $U\left(p_{j}, \tau_{i j}, x_{j}, z_{i}, \xi_{j} ; \theta\right)$, is defined as a function of housing prices $p_{j}$, the property taxes paid by each homeowner $\tau_{i j}$, a vector of housing amenities $x_{j}$, a vector of observed household characteristics $z_{i}$ - including annual household income $I_{i}$, unobserved attributes of the house $\xi_{j}$ and a vector of unknown parameters $\theta$ defining mean and heterogeneity in preferences. I adopt the following functional form:

$$
u_{i j}=\alpha_{i} g\left(I_{i}-p_{i j}\right)+x_{j} \beta_{i}+\xi_{j}+\varepsilon_{i j}
$$

where $g(\cdot)$ is a monotonic function, $\varepsilon_{i j}$ is the stochastic term, and $\alpha_{i}$ and $\beta_{i}$ are preferences for housing prices and attributes. Each parameter associated with the choice variables in the model varies with a household's own characteristics according to: 
(3a) $\quad \alpha_{i}=\alpha_{0}+\sum_{r=1}^{R} \alpha_{r}^{m} z_{r i}$

(3b) $\quad \beta_{i}=\beta_{0}+\sum_{r=1}^{R} \beta_{r}^{m} z_{r i}$

and equations (3a) and (3b) describe household $i$ s preference for housing characteristic $m$. The term $p_{i j}$, which I call the user cost of the house in a given year, is defined as:

$$
p_{i j}=r p_{j}+\tau_{i j}
$$

where $r$ is the annual interest rate. The user cost of the house is composed by a common carrying cost $r p_{j}$ faced by all individuals, and property taxes $\tau_{i j}$ specific to each homeowner.

Alternative choices for the function $g(\cdot)$ determine whether there are income effects in the marginal willingness to pay for amenities. The MWTP by household $i$ for amenity $j$ is:

$$
M W T P_{i j} \equiv-\frac{\frac{\partial u_{i j}}{\partial x_{j}^{m}}}{\frac{\partial u_{i j}}{\partial p_{i j}}}=\frac{\beta_{i}^{m}}{\alpha_{i}} \frac{1}{g^{\prime}\left(I_{i}-p_{i j}\right)}
$$


If $g\left(I_{i}-p_{i j}\right)=I_{i}-p_{i j}$ then the MWTP is just $-\beta_{i}^{m} / \alpha_{i}$. On the other hand, if $g\left(I_{i}-p_{i j}\right)=\log \left(I_{i}-p_{i j}\right)$, as would be the case under a Cobb-Douglas specification of preferences, ${ }^{28}$ then:

$$
\operatorname{MWTP}_{i j}=\frac{\beta_{i}^{m}}{\alpha_{i}}\left(I_{i}-p_{i j}\right)
$$

which is increasing with income net of housing costs.

Given the household's problem described in equations (2)-(4), household $i$ choose housing choice $j$ if the utility that it receives from this choice exceeds the utility that it receives from all other possible house choices, i.e.,

$$
u_{i j}>u_{i k} \Rightarrow W_{i j}+\varepsilon_{i j}>W_{i k}+\varepsilon_{i k} \Rightarrow \varepsilon_{i j}-\varepsilon_{i k}>W_{i k}-W_{i j} \quad \forall k \neq j
$$

where $W_{i j}$ includes all of the non-idiosyncratic components of the indirect utility described in (2). As the inequalities in (7) imply, the probability that a household chooses any particular choice depends in general on the characteristics of the full set of possible house choices.

Assuming $\mathcal{E}_{i j}$ follows an iid extreme value distribution, the probability of household $i$ choosing house $j$ from choice set $J$ has the following functional form:

\footnotetext{
${ }^{28}$ See Berry, Levinsohn and Pakes (1995).
} 


$$
\Pi_{i j}=\frac{\exp \left(\alpha_{i} g\left(I_{i}-p_{i j}\right)+x_{j} \beta_{i}+\xi_{j}\right)}{\sum_{j=1}^{J} \exp \left(\alpha_{i} g\left(I_{i}-p_{i j}\right)+x_{j} \beta_{i}+\xi_{j}\right)}
$$

Maximizing the probability that each household makes the correct housing choice gives rise to the following log-likelihood function:

$$
L=\sum_{i} \sum_{j} 1_{i j} \ln \left(\Pi_{i j}\right)
$$

where $1_{i j}$ is an indicator variable that is equal to one if household $i$ chooses house $j$ and zero otherwise.

\subsection{Endogeneity problems}

The main concern that arises is estimating MW'TP in the framework of equations (2)-(9) comes from the correlation between price and the unobserved portion of the utility. This correlation is caused by omitted variables - the econometrician does not observe all characteristics of the house that affects utility, i.e., prices tend to be higher for houses with valuable unobserved attributes.

Most papers on demand for differentiated products have used two methods to solve this problem: the control function approach or the BLP method. ${ }^{29}$ The main problem with both approaches is the difficulty in finding instruments correlated with price and uncorrelated with the mean utility that all households share from each house. In this paper, I choose the control

\footnotetext{
${ }^{29}$ In the control function, a set of instrumental variables is used in a first stage regression of prices on housing attributes. In the second stage, a function of the first stage predicted residuals is included in the choice model. In the BLP, a series of mean utilities derived from market shares are estimated in the choice model. The mean utilities are then regressed on price, housing variables, and the price instrument.
} 
function approach over the BLP method because of the high number of products in the housing market, leading to complications in estimating mean utilities for each product. ${ }^{30}$

The variation in taxation costs faced by homeowners in California is key element in the identification strategy. The instrument corresponds to the "clean" variation in $p_{i j}$ and it exogenously change according to Propositions 13,60 and 90. Proposition 13 gives the variation in implicit tax benefits faced by homeowners. Propositions 60 and 90 set the moving costs when householders decide to choose another property. A complete investigation of the sources of identification and potential confounding factors is presented in section $5.4 .^{31}$

In practice, I estimate the following first stage for the income effects specification:

$$
g\left(I_{i}-p_{i j}\right)=\lambda \tau_{i j}+x_{j} \psi+v_{i j}
$$

Then, the predicted residual $\hat{v}_{i j}$ is incorporated in the utility function as a linear term:

$$
u_{i j}=\alpha_{i} g\left(I_{i}-p_{i j}\right)+x_{j} \beta_{i}+\delta_{i} \hat{v}_{i j}+\varepsilon_{i j}
$$

where $\delta_{i}$ also depends on observed household characteristics. ${ }^{32}$ As evident from equation (11), the predicted residual $\hat{v}_{i j}$ is a proxy for the unobserved housing quality $\xi_{j} \cdot{ }^{33,34}$ As in traditional

\footnotetext{
30 Bayer, McMillan and Rueben (2003) show under what conditions a mean utility can be estimated to each house. Given the use of houses available in 1989/1990 as the choice set, that approach is not applicable to this study.

${ }^{31}$ In particular, I control for the correlation between property taxes and individual homeowner tenure by looking at property tax averages for individuals of same age living in the same neighborhood.

32 Unobserved heterogeneity is not modeled in this paper because of two reasons. First, the microdata allows me to incorporate a rich set of observed heterogeneity that gives rise to flexible substitution patterns. Second, it is still part of future research how to incorporate BLP type unobserved heterogeneity on models that use random samples of alternatives as a choice set.

${ }^{33}$ It is important to emphasize that the control function approach does not have the same properties of the traditional BLP approach. Petrin and Train (2002) show under what conditions the two methods are similar.
} 
two-stage least squares estimates, the identification strategy fundamentally relies on the first stage results.

While price endogeneity is the main identification problem of revealed preference models, it is not the only one. In order to estimate the model, it is assumed that house characteristics are uncorrelated with the unobserved portion of the utility. As an example, house style or front yard size are assumed to be uncorrelated with number of rooms. If this is not the case, MWTP estimate for an extra room will be biased. Although this might seem a restrictive hypothesis, to my knowledge there is no paper in the housing literature that addresses this question. $^{35}$

\subsection{Estimation results}

This section presents estimation results for the preceding model, using data on 98,407 homeowners between 30 and 70 years of age living in the San Francisco Bay Area and included in the $15 \%$ restricted use 1990 Census sample. ${ }^{36}$ The analysis is restricted to residents of a single metropolitan area for several reasons. First, it is a self-contained economic region, with small proportion of commuters in and out of the region. Second, by focusing on a single metropolitan area, I restrict attention to alternative housing choices in the same area. Finally, for reasons of tractability and for obtaining permission to use the restricted Census data it is more convenient to use data from a single area.

\footnotetext{
${ }^{34} \mathrm{I}$ only include a linear function of the residual in the estimates, although the control function allows the inclusion of any non-linear function. As a consistency check, interactions of the predicted residual with choice variables are included in the model. The results are found to be relatively similar with or without the interactions.

35 Bayer, Ferreira and McMillan (2003) use boundary fixed effects to control for the correlation between unobserved quality of the neighborhood and observed neighborhood characteristics but use similar assumption for housing characteristics. All other revealed preference papers, including the non-housing literature, generally assume that all covariates (but price) are uncorrelated with unobserved quality of the relevant product. An exception to this rule is Chay and Greenstone (2001). They instrument pollution levels with the Clean Air Act of 1975 to estimate MWTP for air quality

36 The sample is composed of six counties: Alameda, Contra Costa, Marin, San Jose, Santa Clara and San Francisco.
} 
In the estimation, each household is assumed to compare the value of their current house to the value of a set of alternative houses. I assume that the set of possible alternatives includes houses that were newly purchased in the previous year. This is best proxy for houses available in the market in the year of analysis. ${ }^{37}$ For each household in the estimation sample, I randomly assign 10 alternative houses from the choice set. ${ }^{38}$

The choice variables include characteristics of the house (draw from the Census data), socio-demographic characteristics of the neighborhood (based on averages at the block group level from the Census data), and characteristics of the neighborhood from external data, including elevation, population density, a measure of local air quality and a measure of $1^{\text {st }}$ grade test scores in the nearest public primary school. ${ }^{39}$

Table 6 shows the average characteristics of the houses owned by people in the sample and of the alternative houses. The alternative houses have a smaller number of rooms, were built more recently and are more likely to be apartments or attached dwellings. Neighborhood characteristics are very similar for both groups, although chosen houses are located in slightly whiter and richer block groups.

From the point of view of the model developed in the last section, the most interesting feature of the chosen house versus the alternatives is the property tax. For the chosen houses,

\footnotetext{
${ }^{37}$ Misspecification of the choice set may lead to serious estimation biases. Swait (1984) showed, for example, that not incorporating captivity to a certain group of alternatives, lead to downward biased estimates for choice characteristics and upward biased fixed effects parameters. The logic is simple: when we include in the model alternatives not available to individuals (or not considered by them), we are in fact adding extra noise, which will be captured by the fixed effects, reducing the importance of observed choice variables.

38 The consistency of this procedure is guaranteed by the IIA property - see McFadden (1978). Although IIA property dictates substitution patterns among individual alternatives, the inclusion of observed heterogeneity allows flexible substitution patters at higher levels of aggregation. Also, the inclusion of distance to work gives rise to more reasonable substitution patterns in the urban space.

${ }^{39}$ Elevation is measured at the block level (source: EPA: BASINS - Better Assessment Science Integrating Point and Nonpoint Sources). Population density combines Census data and block group areas drawn from ArcView GIS. Average test scores of 1991-1992 and 1992-1993 academic years are assigned from the closest school within the school district, using census block centroids and school latitudes and longitudes (source: California Department of Education, 1991-1993). Air quality is predicted for each census block using information from monitor stations (source: Rand California, 1990) and industrial plants (source: EPA - AIRS -Aerometric Information Retrieval System).
} 
the property tax is reported in the Census. For the alternative, the institutional framework of Propositions 13, 60 and 90 is used to generate the taxation costs that a specific household faces when choosing that house. For example, a 30 year old choosing a house from the alternative set is assumed to have property taxes calculated as $1 \%$ of the house value. ${ }^{40}$ On the other hand, homeowners age 55 or older are allowed to transfer current property tax cost of their current home to another house if: a) the housing alternative is of equal or lesser value; b) the homeowner is moving within the same county or to a county that accepts Proposition 90. After generating property taxes for all alternatives, the individual user cost of the house is constructed as in equation 8 , using an interest rate of $6 \%$. Appendix Table 1 reports the first stage estimates of the user cost on property taxes and housing and neighborhood variables for the pooled set of houses and alternatives. As expected, all specifications show a high F-test for the instrumental variable.

Multinomial logit estimates are presented in Table 7. Column (1) shows preference parameters for a model without heterogeneity and assuming that utility is linear in income net of housing costs. I focus on three variables - number of rooms, detached houses and average income of the neighborhood - to compare how changes in the model affect housing and neighborhood MWTP estimates. All signs look correct - negative for price and positive for the choice variables. The main problem is the magnitude of the price coefficient, which suggests a very small value for the marginal utility of income, or alternatively very high value of willingness to pay. This problem, which has been noted in other studies, ${ }^{41}$ is arguably due to the fact that house prices are correlated with unobserved characteristics of the house. Looking at columns (2)-(4), the estimated coefficient of the user cost variable remains relatively small in magnitude, even when including a broad set of housing and neighborhood controls.

40 Self-reported house values from the Census are used to calculate this cost.

41 See Petrin and Train (2002) and Bayer, McMillan and Rueben (2002), for example. 
Column (5) reports the estimate results for a specification similar to the one in column (4) but with the addition of a control function, equal to the residual of the first stage model for the user costs, as indicated in equations (10) and (11). The coefficient on the control function is large and positive, suggesting that unobserved variables that affect price also affect the utility assigned to the house. When the control function is included, the coefficient on the user cost rises in magnitude by a factor of 10 .

MWTP estimates derived from the primitives of the model are shown in Table 8. The simplest model shows very high MWTP estimates for housing characteristics - $\$ 3,275$ per year for an extra room and $\$ 17,210$ for a detached house. On the other side, MWTP for average income of the neighborhood seems too small - $\$ 1,081$ for a $\$ 10,000$ higher average income of the neighborhood. Even after including other controls for housing and neighborhood amenities, the results still look very similar. Column (5) shows the inclusion of the control function. As noted in the multinomial logit estimates, the control function has the expected effect of deflating the MWTP estimates for housing characteristics $(\$ 1,754$ for number of rooms and $\$ 4,186$ for a detached house) and increasing the MWTP for average income $(\$ 1,381)$.

A last change in the model is the inclusion of observed heterogeneity. Household income, age, and a dummy for white are interacted with all choice characteristics, including distance to work. The inclusion of heterogeneity only partially affects the estimates, as noted in column (6). The final MWTP numbers are $\$ 1,854$ per year for an extra room, $\$ 4,088$ for a detached house and $\$ 1,322$ for a $\$ 10,000$ higher average income of the neighborhood. These numbers correspond to a baseline white household with average income and average age. ${ }^{42}$

Finally, wealth effects are included in columns (8) and (9). Again, the results are meaningful only after controlling for unobserved housing quality. The user cost coefficient sign

42 Estimates in columns (6)-(9) use only 6 alternatives because the model with heterogeneity was not computationally feasible to estimate with 10 alternatives. 
is opposed to the initial estimates because of the use of income net of housing costs. The numbers are $\$ 6,135$ for number of rooms, $\$ 19,749$ for a detached house and $\$ 4,758$ for average income of the neighborhood. In order to compare MWTP estimates with and without wealth effects, we first need to normalize the estimates by the correspondent monetary measure - the average user cost and the average income net of user cost. When wealth effects from owning a property are considered in the model, homeowners are on average willing to pay $25 \%$ more for an extra room and for average income, and 75\% more for a detached house.

When comparing these numbers with hedonic price regressions in Table 11, there are large differences for the wealth effects specification, with detached house having a negative sign for the MWTP estimate. The differences are also large for housing characteristics in the specification free of wealth effects, but similar results are found for average income.

An interesting way of testing the fitness of the residential demand model is to look at predicted mobility rates. The estimated probabilities of choosing a house from the alternative set are used as a proxy for mobility. ${ }^{43}$ Figure 15 plots these predicted probabilities by age groups. The predicted mobility patterns only resemble the ones showed in Figure 3 when using the final specification of the model. When not using the variation in property taxes to control for unobserved components of the house, predicted mobility patterns are almost constant across age groups. $^{44}$

\subsection{Sources of identification}

The identification strategy used in the previous section relied on homeowner specific moving costs determined by Propositions 13, 60 and 90. In this section, I provide tests to

\footnotetext{
43 Predicted probabilities of choosing a house are estimated directly from equation 8.

${ }^{44}$ Both predictions were normalized to the observed mobility rates at age 54 . When comparing predicted mobility patterns in levels for the models with and without the control function, it is observed an overall decrease in mobility rates after the inclusion of the unobserved component.
} 
identify the role of each of these propositions. The implicit tax benefit from Proposition 13 is the dominant source of variation. Because of the correlation between homeowner tenure and the tax benefit from Proposition 13, I provide an adjustment to ridit of this source of bias from the instrumental variable. Furthermore, an additional validity test on the functional form of the control function is presented at the end of the section.

In the first test, I apply to the Dallas-TX in 1990 data the same control function approach used to estimate housing demand for the San Francisco Bay Area. ${ }^{45}$ Table 10 shows the multinomial logit estimates for the models with and without the control function. Although the control function term in column (2) has a significant coefficient, its magnitude is very small compared to a corresponding model applied to the California data (Table 7, column (5)). Table 11 reports the respective MWTP estimates. Results are very similar for both approaches, indicating that the control function does not provide new relevant variation to the estimates. Given that house values in Texas are re-assessed every two to three years, moving costs represented by property taxes are highly correlated with house values. This is confirmed by the first stage estimates in Appendix Table 1, where the user cost regressed on house characteristics and the instrument has an $\mathrm{R}^{2}$ of .99 .

In the next test, the institutional framework of Proposition 60 is simulated in Dallas-TX. The basic premise of this simulation is to allow homeowners in Texas to transfer their current property taxes to a house in the choice set, according to Proposition 60 rules. ${ }^{46}$ If the structure alone were driving the estimates, then one would expect results from this simulation to mirror those from the San Francisco Bay Area. As observed in column (3) of Table 10, however, the

\footnotetext{
45 The public use Census data was used to estimate the model for Dallas-TX. This was due to delays in getting access to the Texas restricted Census micro data.

${ }^{46}$ If the homeowners are 54 years of age or younger, then property taxes for the alternative houses are set at $1.4 \%$ of the house value - which corresponds to the average effective property taxes in Dallas. If homeowners are 55 years of age or older, they are allowed to transfer the tax benefit (if it is profitable to do so).
} 
simulated structure does not guarantee a strong first stage, and the MWTP estimates are very similar to the model without Proposition 60.

These tests indicate that the variation in property taxes due to Proposition 13 is driving the results. The intuition is that Proposition 13 is the source of individual specific monetary losses that occur when homeowners move to another house. In order to confirm this idea, I estimate a model for a sub-sample of homeowners from ages 30 to 49. This selection of homeowners rules out incentives in delaying mobility for individuals close to 55 year of age as the relevant variant of the instrument. Columns (4) and (5) in Table 11 show the results for the 30 to 49 -year old sub-sample. The estimates reveal patterns similar to those found in the full sample, with the control function working effectively.

Interestingly, the tax benefit alone is not enough to shift the estimates. Column (6) reports results from a model that simulates households being allowed to transfer their tax benefit to another house without restrictions. The first stage, as reported in Appendix Table 1, is not strong enough and MWTP estimates are meaningless because of the lack of variation in moving costs. This is confirmed when estimating a model for a second sub-sample, now composed of 60 to 70 -year old homeowners. As reported in Table 11, the control function is effective because homeowners cannot transfer the tax benefit to all houses nor is it not profitable to do so $^{47}$ On the other hand, when I simulate unrestricted transfer benefits in column (9), the estimates are meaningless because of the lack of variation in the first stage.

A potential concern about using moving costs as source of identification is the instrument's correlation with homeowner tenure. If the instrument is correlated with tenure, then it is also potentially correlated with unobserved housing quality, undermining the identification strategy. A simple regression of property taxes on tenure produces an $\mathrm{R}^{2}$ of .15.

${ }^{47}$ For example, when the new house has a very small price and the tax benefit is higher than $1 \%$ of the new house value. 
In order to address this issue, an alternative specification is used for the instrument, where the variable individual tenure is decomposed out of moving costs. I then apply the adjusted instrument to the 30 to 49 -year old sample and compare the estimates with the initial instrument.

The procedure works as follows: First, the effective property tax rates are estimated for each homeowner. Then, block group average effective tax rates are calculated for homeowners in four age groups, namely 30-34, 35-39, 40-44 and 45-49 year olds. Finally, the house value of each homeowner is multiplied by the relevant average effective tax rate. In doing so, the correlation of the instrument with individual homeowner tenure is mitigated, leaving an adjusted property tax that is a function of past housing values in the same neighborhood for people of the same age group. As expected, I find an $\mathrm{R}^{2}$ of only .04 for the regression of the adjusted instrument on homeowner tenure. Column (7) in Table 11 shows the estimates for a model that uses the adjusted instrument. Although standard errors are higher than in the model with the regular instrument, MWTP estimates are relatively similar - the main difference is that estimates for average income of the neighborhood increases from $\$ 1,197$ to $\$ 1,602$.

A final robustness check is performed on the functional form of the utility function. The unobserved quality of the housing component was assumed to be separable additive in both the utility function and the first stage regression. If this is not the case, estimates from the model are potentially biased. To address this concern, the predicted residual is interacted with the choice variables in the model. Column (7) in Table 8 shows small differences between the results with or without the interaction terms, besides the expected increase in standard errors.

\section{Conclusion}

Given that homeownership is the primary way in which families accumulate wealth, 
understanding housing demand is of special importance in evaluating questions of welfare and equity across household types. Unfortunately, existing economic models that predict sorting in the urban landscape generally assume no barriers to household sorting due to transaction costs. In reality, it is hardly credible to assume that such frictions do not affect the housing market.

In this paper I provide clear evidence that transaction costs affect individual behavior. Using a natural experiment design generated by California's Propositions 13, 60 and 90, I show a distinct effect of property tax variations on household mobility. This analysis also indicates that individuals may face differentiated prices in the market and that such variation can be used as a source of identification for revealed preference models of housing demand. Given this evidence, economic models that fail to incorporate these moving costs may provide biased predictions of choice behavior.

This study leads me towards two other areas of research to be explored in future work. First, the housing market has important dynamic components that have been neglected in the existing literature. Despite a woeful lack of panel data, there is still much that can be learned with the combination of theoretical modeling and cross-sectional comparisons. Second, the welfare consequences of barriers to optimal housing sorting have yet to be analyzed. This is of special interest to understanding the effects of transaction costs on neighborhood composition, and on housing consumption patterns of younger families. 


\section{References}

Akerlof, G., Rose, A. and Yellen, J. (1990) "Waiting for Work." National Bureau of Economic Research Working Paper, \#3385.

Auerbach, A. (1992) “On the Design and Reform of Capital Gains Taxation.” National Bureau of Economic Research Working Paper, \#3967.

Bajari, P. and Kahn, M. (2001) "Why do Blacks Live in The Cities and Whites Live in the Suburbs?” mimeo, Stanford University.

Benabou, Roland, (1993), "The Workings of a City: Location, Education, and Production," Quarterly Journal of Economics, 108(3), pp.619-652.

Barrow, L. and Rouse, C. (2000) "Using Market Valuation to Asses the Importance and Efficiency of Public School Spending.” Working Paper, Princeton University.

Bayer, P., McMillan, R. and Rueben, K. (2002) "The Causes and Consequences of Residential Segregation: An Equilibrium Analysis of Neighborhood Sorting.” Mimeo, 2002.

Bayer, P., Ferreira, F. and McMillan, R. (2003) "A Unified Framework for Measuring Preferences for Schools and Neighborhoods.” NBER Summer Institute, 2003.

Ben-Akiva, M. and Boccara, B. (1995) "Discrete Choice Models with Latent Choice Sets." International Journal of Research in Marketing, 12, p. 9-24.

Berry, S. (1994) "Estimating Discrete-Choice Models of Product Differentiation." The Rand Journal of Economics, Vol. 25(2), p. 242-262.

Berry, S., Levinsohn, J. and Pakes, A. (1995) "Automobile Prices in Market Equilibrium." Econometrica, Vol. 63(4), p. 841-890.

Blundell and Powell (2001) "Endogeneity in semiparametric binary response models." Working Paper, Department of Economics, University College London.

Brunner, E. and Rueben, K. (2001) "Financing New School Construction and Modernization: Evidence from California.” National Tax Journal, 54(3), p. 527-39.

Caplin, A., Freeman,C. and Tracy, J. (1997) "Collateral Damage: Refinancing Constraints and Regional Recessions.” Journal of Money, Credit and Banking, 29(4), p.496-516.

Chan, S. (2001) "Spatial Lock-In: Do Falling House Prices Constrain Residential Mobility." Journal of Urban Economics, Vol. 49(3), p. 567-586. 
Chay, K. and Greenstone, M. (2000) "Does Air Quality Matter? Evidence from the Housing Market.” Mimeo, UC Berkeley.

Epple, D., R. Filimon, and T. Romer (1984) "Equilibrium Among Local Jurisdictions: Towards an Integrated Approach of Voting and Residential Choice," Journal of Public Economics, Vol. 24, pp. 281-304.

(1993) "Existence of Voting and Housing Equilibrium in a

System of Communities with Property Taxes,” Regional Science and Urban Economics, Vol. 23, pp. 585-610.

Epple, D. and Sieg, H. (1999) "Estimating Equilibrium Models of Local Jurisdictions," Journal of Political Economy, Vol. 107, No. 4., pp. 645-681.

Epple, D. and Zelenitz, A. (1981) “The Implications of Competition Among Jurisdictions: Does Tiebout Need Politics?’ The Journal of Political Economy, 89, pp. 1197-1217.

Ferreira, F. (2003) “General Equilibrium Consequences of Transaction Costs on Neighborhood Sorting." Mimeo, UC Berkeley.

Fischel, W. (1989) “Did Serrano Cause Proposition 13?” National Tax Journal, 42(4), p. 465-73.

Hausman, J. (1978) “Specification tests in econometrics.” Econometrica, 46, p. 1251-1272.

Heckman, J. (1978) "Dummy endogenous variables in a simultaneous equation system." Econometrica ,46, p. 931-959.

Madrian, B. (1994) "Employment-Based Health Insurance and Job Mobility: Is There Evidence of Job-Lock?” Quarterly Journal of Economics, 109(1), p. 27-54.

Manski, C. (1983) "Identification of Endogenous Social Effects: The Reflection Problem." Review of Economic Studies, 60, p. 531-542.

McFadden, D. (1974) "Conditional Logit Analysis of Qualitative Choice Behavior." Frontiers in Econometrics, Academic Press: New York, p. 105-142.

(1978) "Modeling the Choice of Residential Location." In A. Karlqvist, L. Lundqvist, F. Snickars and J. Weibull (eds.). Spatial Interaction Theory and Planning Models, North Holland: Amsterdam, p. 75-96.

Nagy, J. (1997) "Did Proposition 13 Affect the Mobility of California Homeowners?" Public Finance Review, 25(1), p. 102-16.

Nechyba, Thomas J., (1997), "Existence of Equilibrium and Stratification in Local and Hierarchical Tiebout Economies with Property Taxes and Voting," Economic Theory, Vol. 10, pp. $277-304$. 
Nevo, A. (2000) “A Practitioner's Guide to Estimation of Random Coefficients Logit Models of Demand." Journal of Economics and Management Strategy, Vol. 9(4), p. 513-548.

Palmquist, R. (1984) "Estimating the Demand for the Characteristics of Housing." The Review of Economics and Statistics, Vol. 6(3), p. 394-404.

Petrin, A. and Train, K. (2002) "Omitted Product Attributes in Discrete Choice Models." Mimeo, University of California, Berkeley.

Quigley, J. (1985) “Consumer Choice of Dwelling, Neighborhood and Public Services.” Regional Science and Urban Economics, Vol. 15, p. 41-63.

(1987) “Interest Rate Variations, Income, and Home Improvement Decisions." Review of Economic and Statistics, 69(4), p. 636-643.

(2002) “Transaction Costs and Housing Markets.” Mimeo, University of California, Berkeley.

Rosen, K. (1982) “The Impact of Proposition 13 on House Prices in Northern California: A Test of the Interjurisdictional Capitalization Hypothesis.” Journal of Political Economy, 90(1), p. 191-200.

Rosen, S. (1974) "Hedonic Prices and Implicit Markets: Product Differentiation in Pure Competition." The Journal of Political Economy, Vol. 82(1), p. 34-55.

Rothstein, Jesse, (2002), “Good Principals or Good Peers: Parental Valuation of School Characteristics, Tiebout Equilibrium, and the Incentive Effects of Competition Among Jurisdictions". mimeo, University of California, Berkeley.

Rubinfeld, D. (1987) “Economics of the Local Public Sector." In: Auerbach, A. and Feldstein, M. eds., Handbook of Public Economics, vol.2, chapter 11.

Rueben, K. and Cerdan, P. (2003) "Fiscal Effects of Voter Approval Requirements on Local Governments." Public Policy Institute of California, San Francisco, California.

Sexton, T., Sheffrin, S. and O’Sullivan, A. (1995) "Property Taxes, Mobility, and Home Ownership." Journal of Urban Economics, 37, p. 107-129.

(1995a) "Property Taxes and Tax Revolts: The legacy of Proposition 13". New York: Cambridge University Press.

(1999) "Proposition 13: Unintended Effects and

Feasible Reforms.” National Tax Journal, 52(1), p. 99-111.

Shapiro, P. and Sonstelie, J. (1982a) "Did Proposition 13 Slay Leviathan?" American Economic Review, 72(2), p. 184-90. 
(1982b) "Representative Voter or Bureaucratic Manipulation:

An Examination of Public Finances in California before and after Proposition 13." Public Choice, 39(1), p. 113-42.

Sheppard, S. (1999) “Hedonic Analysis of Housing Markets.” In Cheshire, P. and Mills, E., eds., Handbook of Regional and Urban Economics, vol. 3. North-Holland, New York.

Silva, F. and Sonstelie, J. (1995) "Did Serrano Cause a Decline in School Spending?" National Tax Journal, 48(2), p.199-215.

Smith, R. and Blundell (1986) “An Exogeneity Test for a Simultaneous Equation Tobit Model with an Application to Labor Supply." Econometrica, 54, p. 230-239.

Swait, J. (1984) Probabilistic Choice Set Formation in Transportation Demand Models. Unpublished Ph. D. Dissertation, MIT, Cambridge, MA.

Train, K. (2003) Discrete Choice Methods with Simulation. Cambridge University Press.

Tiebout, C. (1956) “A Pure Theory of Local Expenditures.” The Journal of Political Economy, Vol. 64(5), p. 416-424.

Villas-Boas, J. and Winer, R. (1999) "Endogeneity in brand choice models." Management Science, 45, p. 1324-1338. 
Figure 1. Effective property tax rates by homeowner age, California 1990.

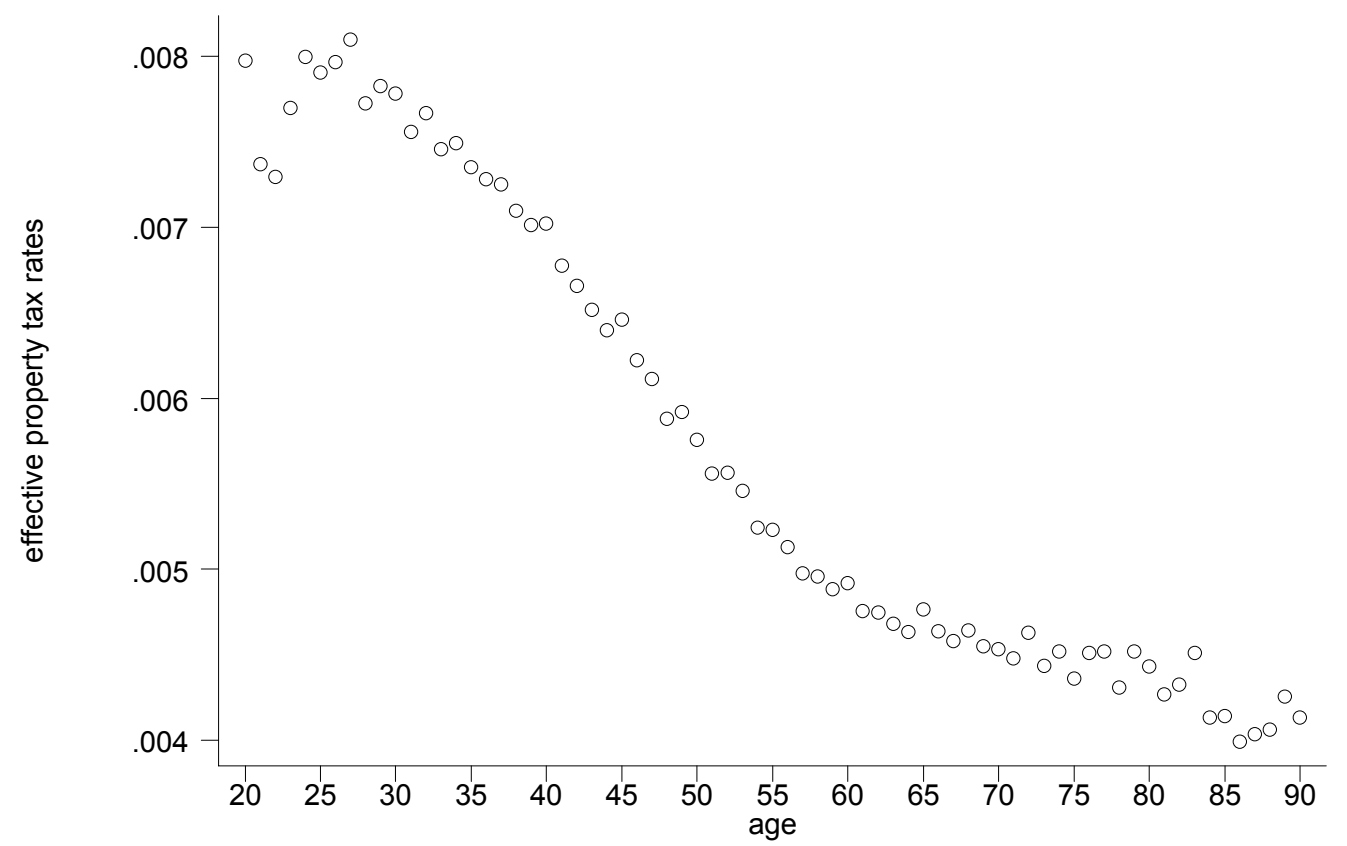

Source: 1990 IPUMS. Notes: Effective property tax rates are calculated as property taxes divided by house values. Age is the maximum between age of the head of the house and spouse.

Figure 2. Property taxes/household income ratio by age, California 1990.

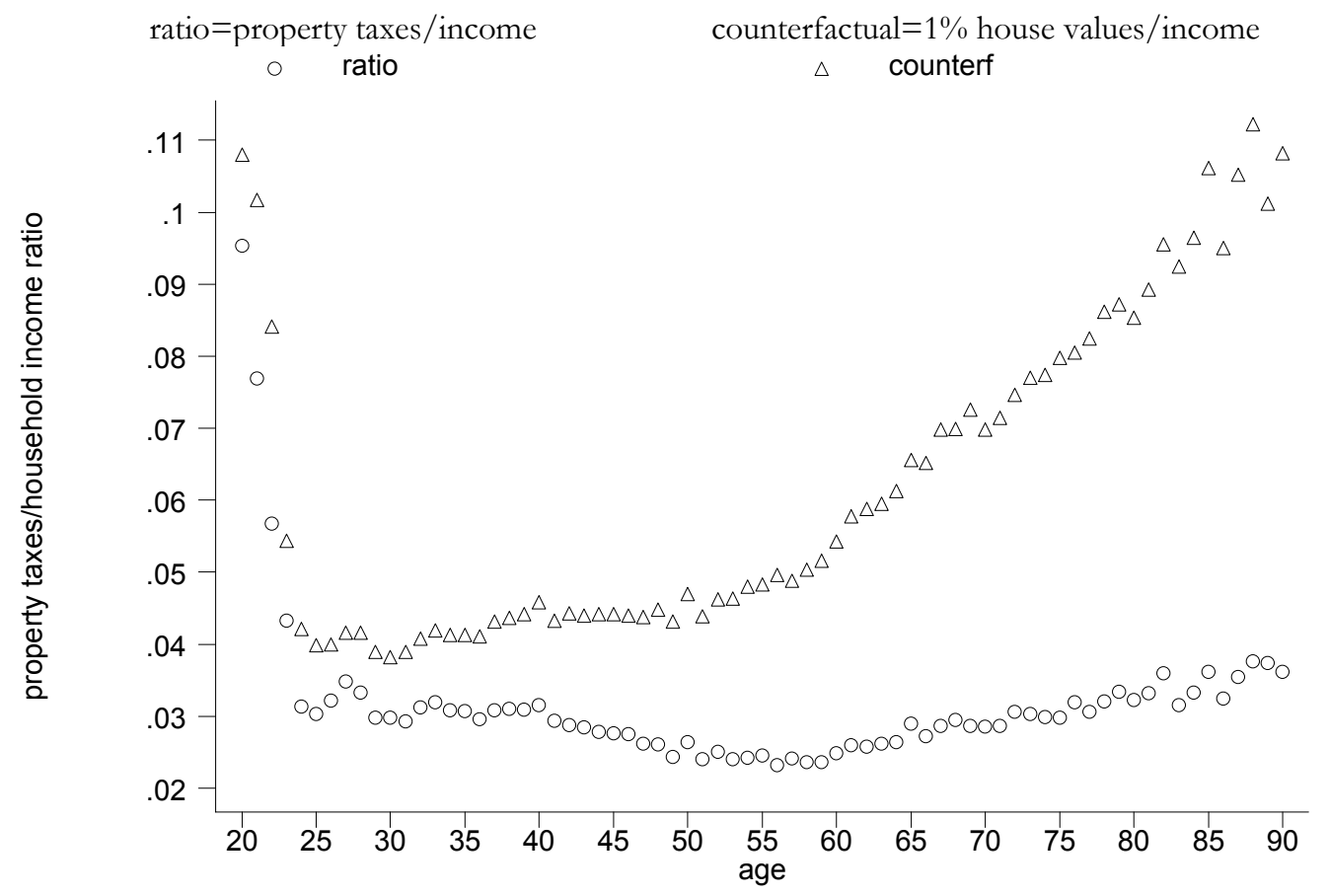

Source: 1990 IPUMS. Notes: Counterfactual ratios are calculated as 1\% of house values divided by household income. Age is the maximum between age of the head of the house and spouse. 
Figure 3. Property taxes/household income ratio by income quantile, California 1990.

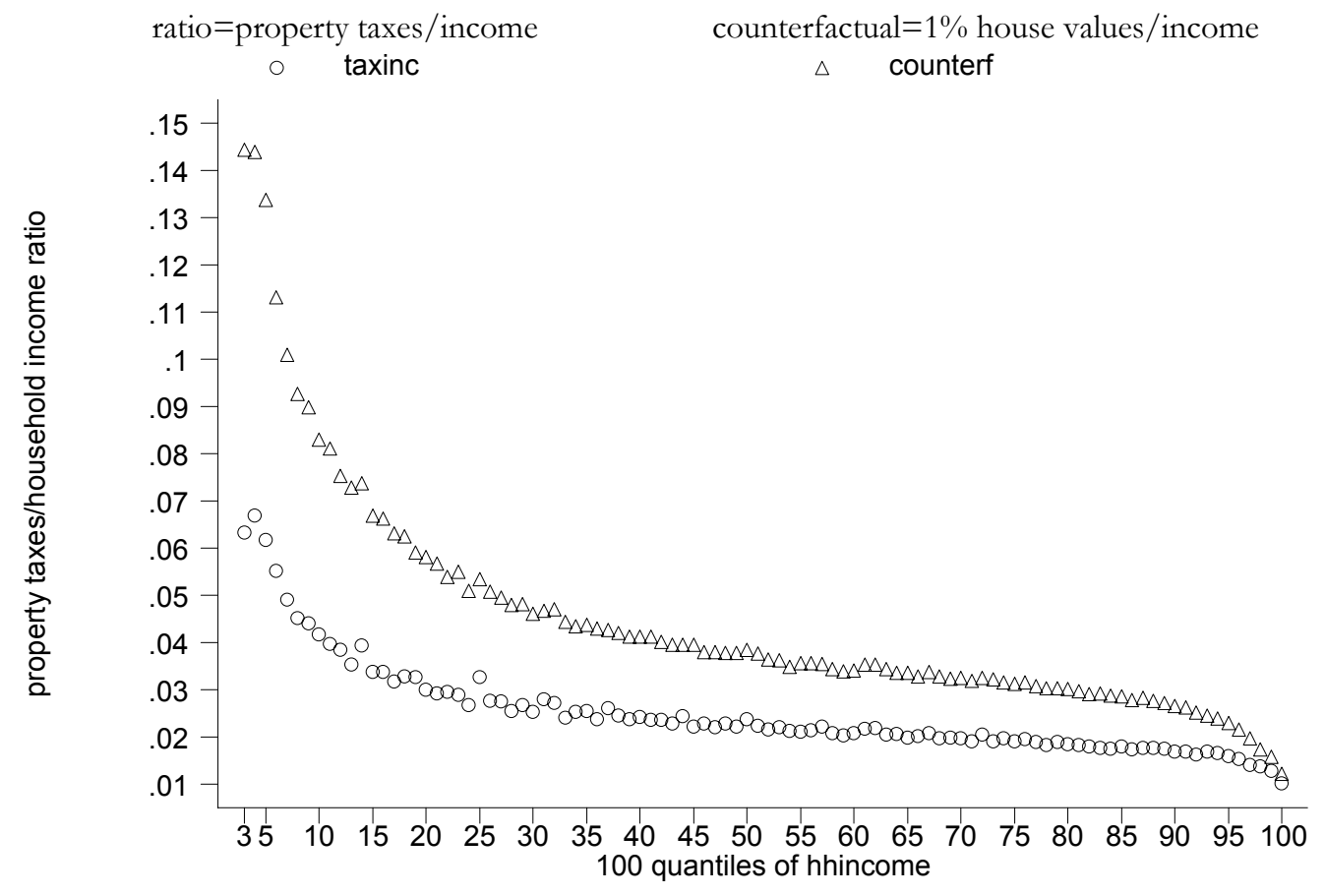

Source 1990 IPUMS. Notes: Counterfactual ratios are calculated as 1\% of house values divided by household income. Age is the maximum between age of the head of the house and spouse.

Figure 4. Probability of moving for homeowners by age, California 1990.

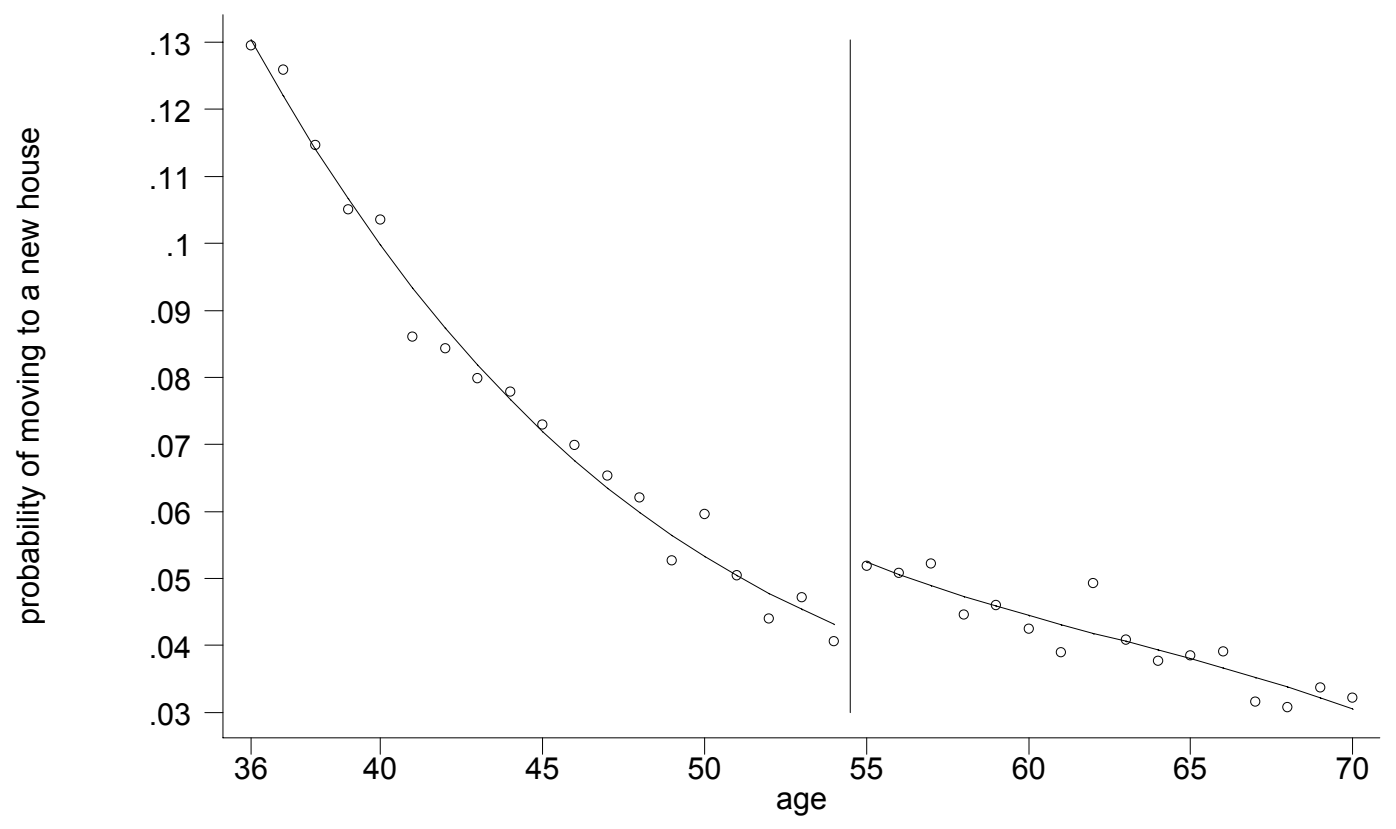

Source: 1990 IPUMS. Notes: Each dot represents the probability of moving for homeowners by age, calculated as the number of new movers in 1989-1990 divided by the total number of homeowners by age. Age is the maximum between age of the head of the house and spouse. The thick line is composed by predicted values of a polynomial regression of probability of moving on age, dummy for 55-year or older and interactions of these components. 
Figure 5. Probability of moving for homeowners by age, California 1980.

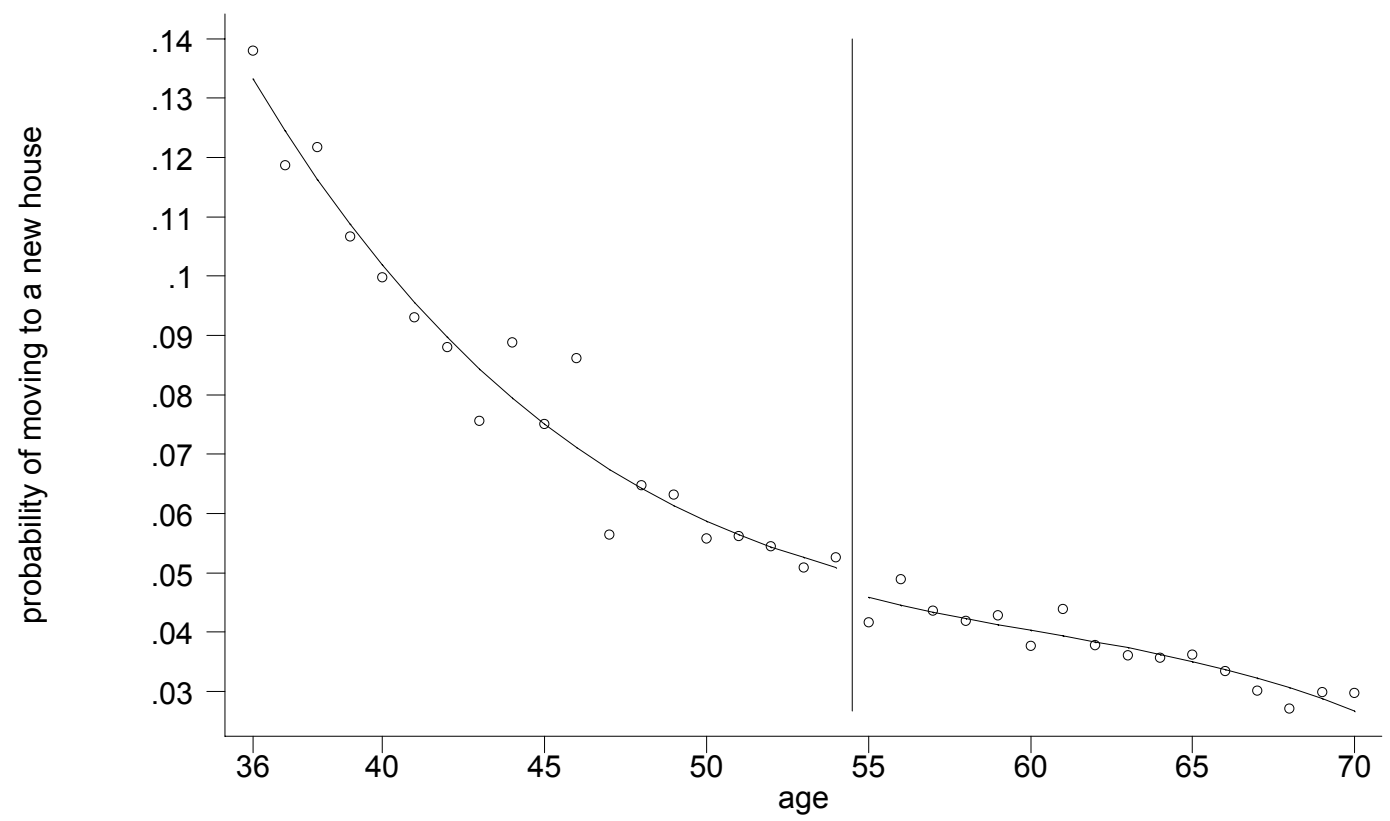

Source: 1980 IPUMS. Notes: Each dot represents the probability of moving for homeowners by age, calculated as the number of new movers in 1979-1980 divided by the total number of homeowners by age. See Figure 4 for other details.

Figure 6. Probability of moving for renters by age, California 1990.

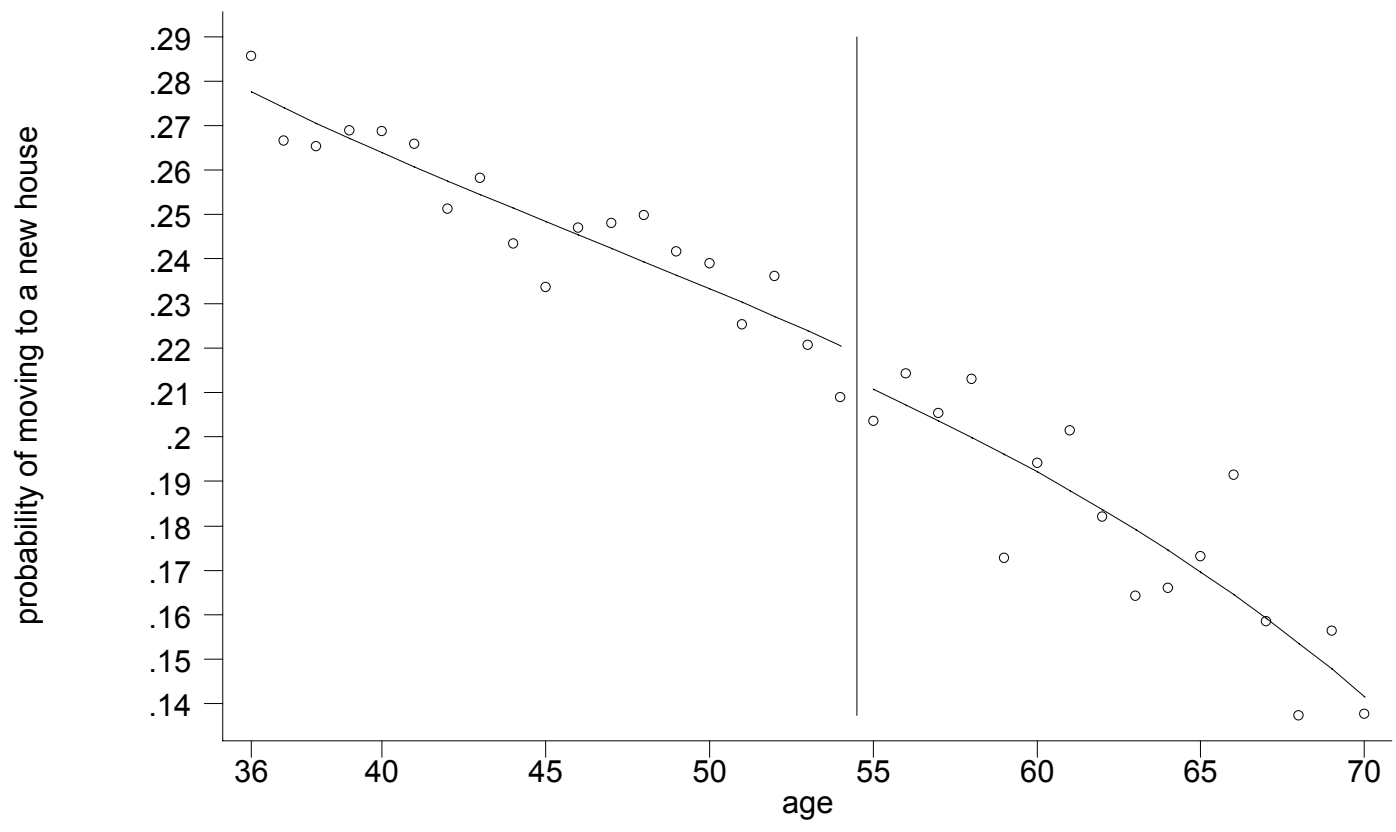

Source: 1990 IPUMS. Notes: Each dot represents the probability of moving for renters by age, calculated as the number of new renters in 1989-1990 divided by the total number of renters by age. See Figure 4 for details. 
Figure 7. Probability of moving for homeowners by age, Texas 1990.

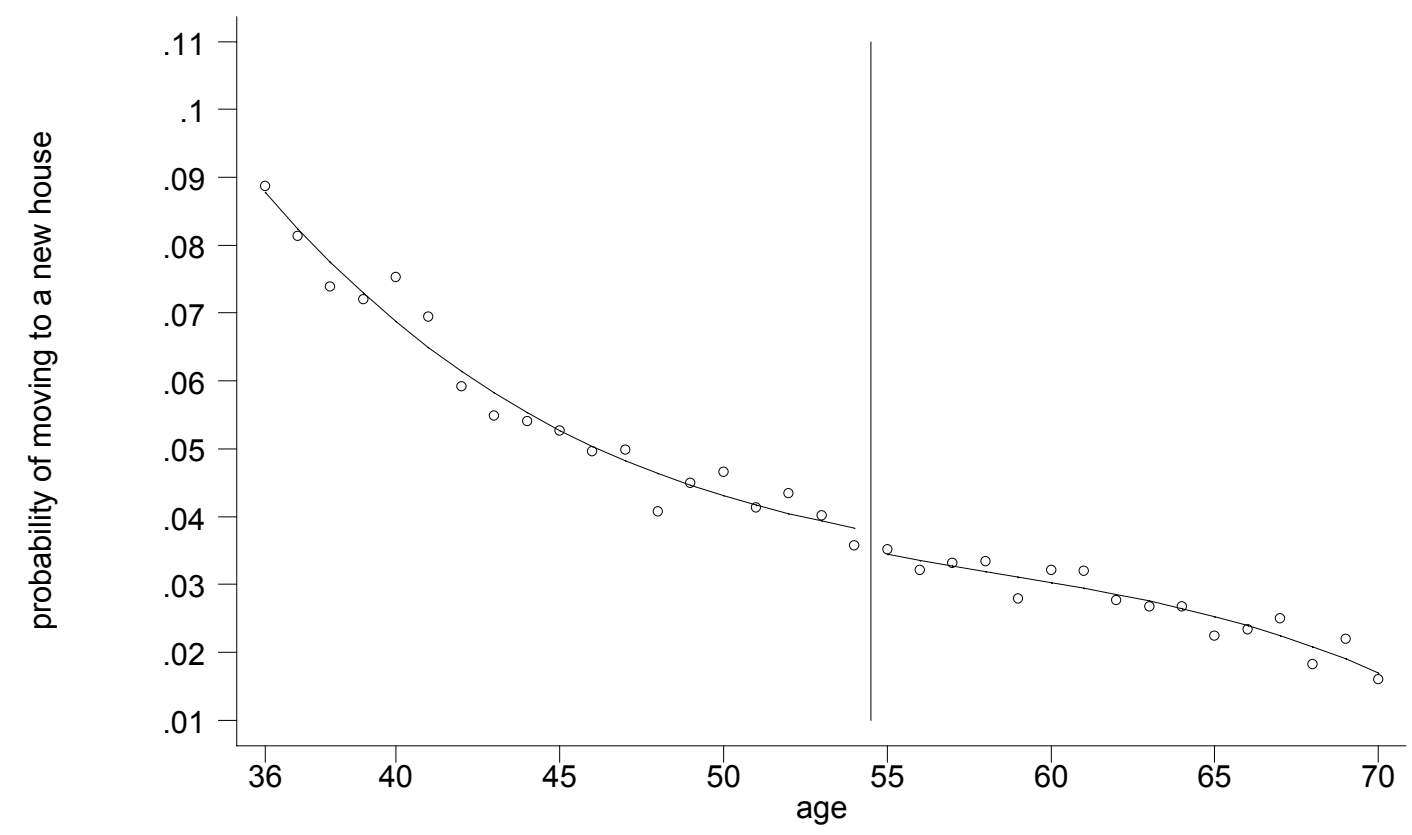

Source: 1990 IPUMS. See Figure 4 for details.

Figure 8. Average property taxes for 1989-1990 movers by age, California 1990.

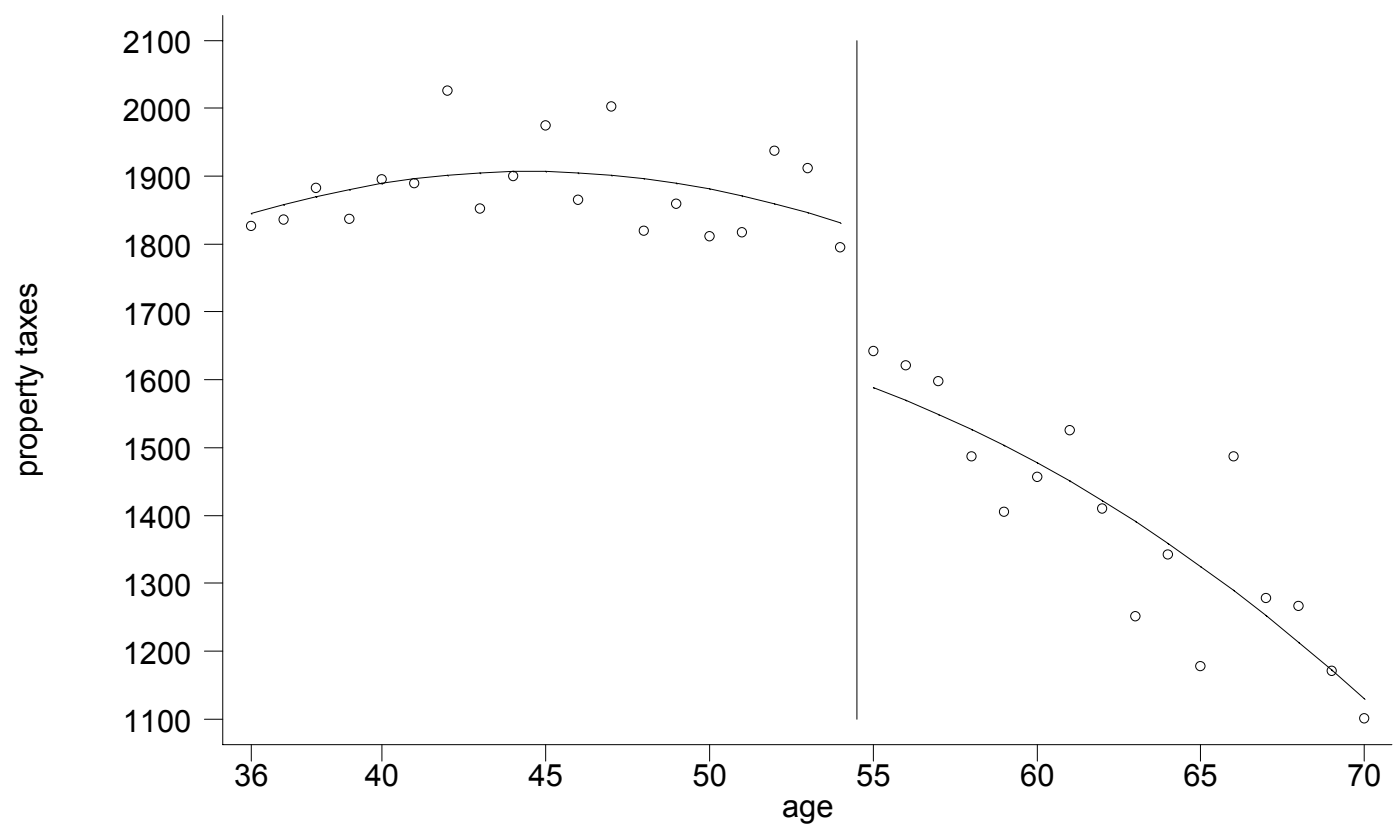

Source: 1990 IPUMS. Notes: Each dot represents the average property taxes faced by each age group. See Figure 4 for details. 
Figure 9. Average property taxes for 1979-1980 movers by age, California 1980.

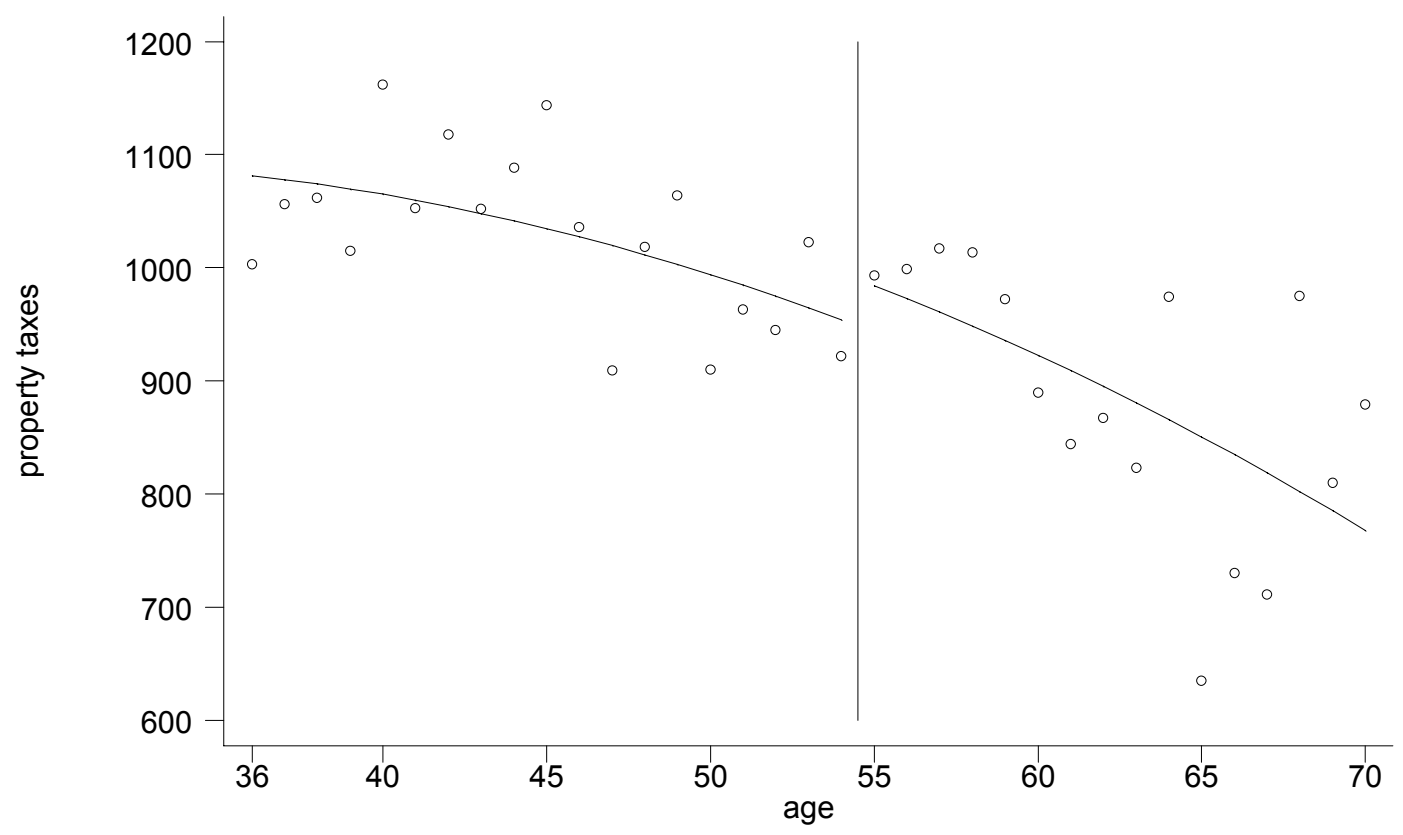

Source: 1980 IPUMS. Notes: Each dot represents the average property taxes faced by each age group. See Figure 4 for details.

Figure 10. Average property taxes for 1989-1990 movers by age, Texas 1990.

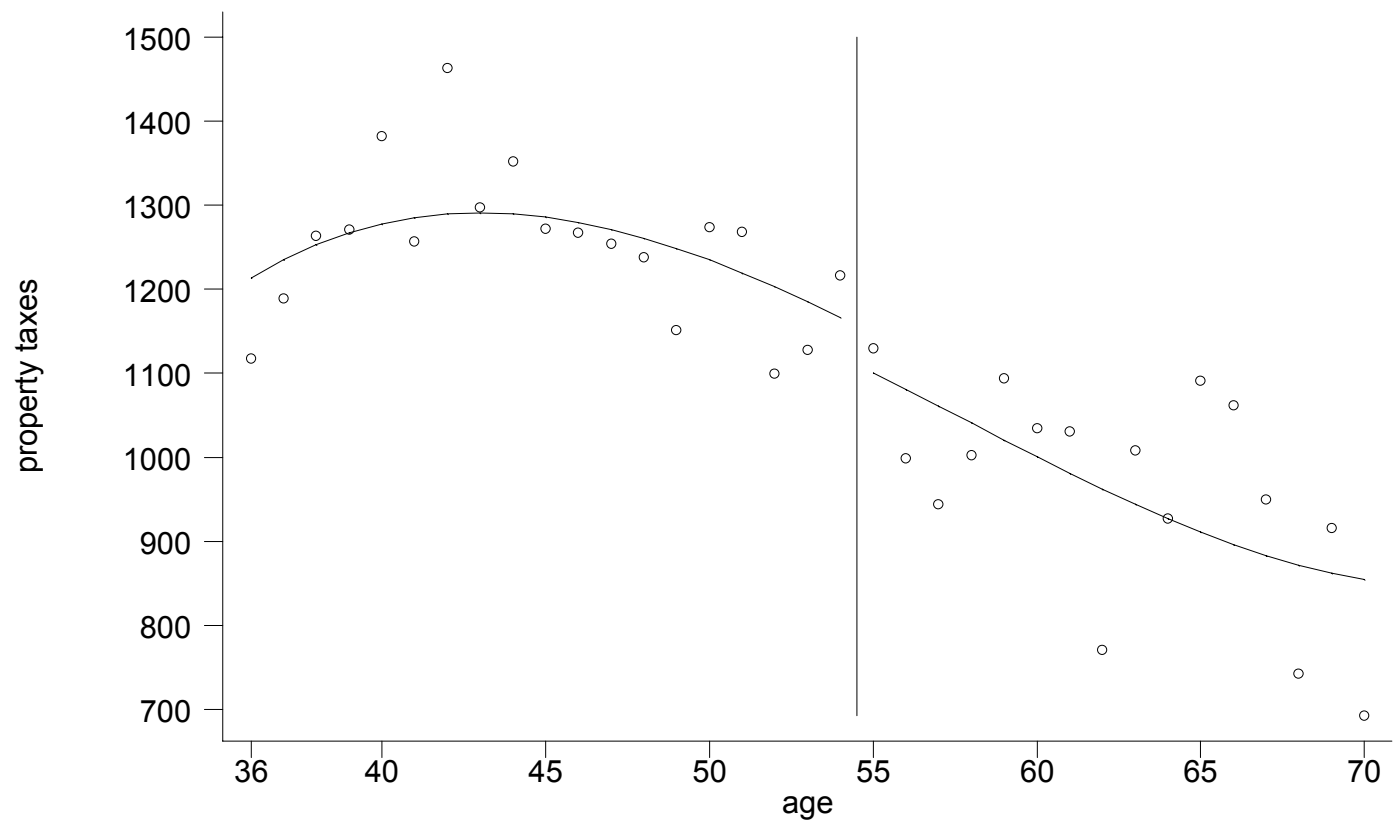

Source: 1990 IPUMS. Notes: Each dot represents the average property taxes faced by each age group. See Figure 4 for details. 
Figure 11. Average effective property tax rates for 1989-1990 movers by age, California 1990.

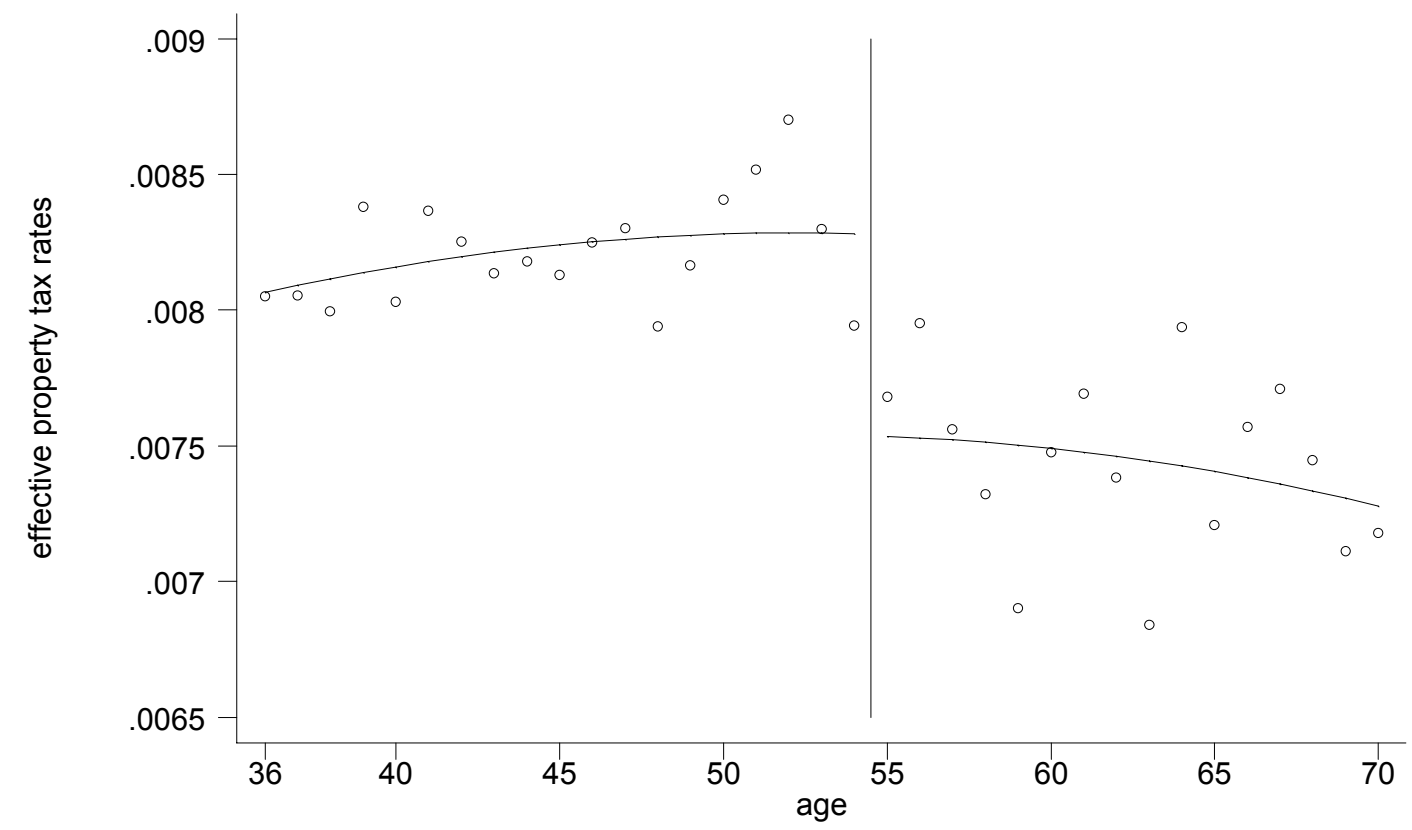

Source: 1990 IPUMS. Notes: Each dot represents the average effective tax rates faced by each age group. See Figure 4 for details.

Figure 12. Average effective property tax rates for 1979-1980 movers by age, California 1980.

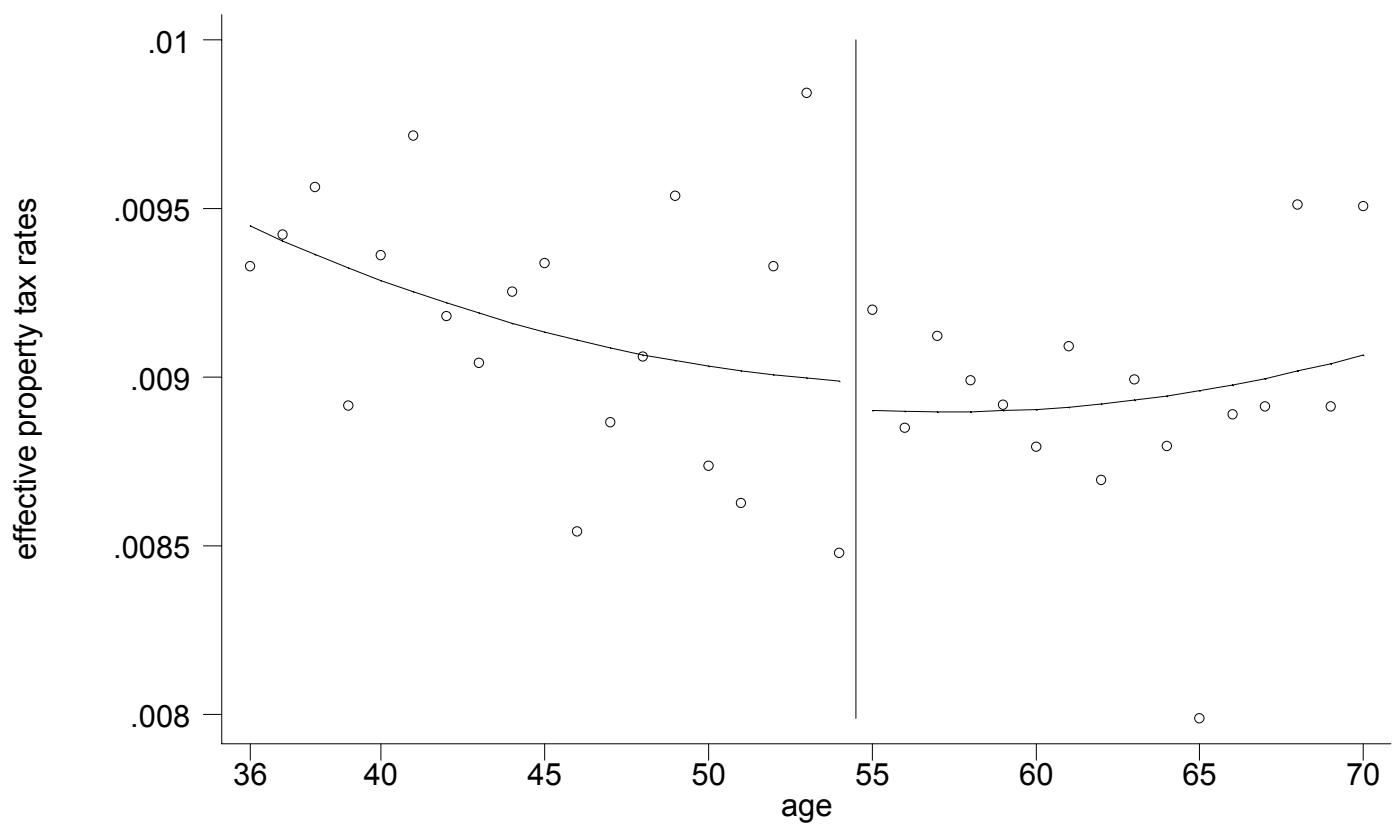

Source: 1980 IPUMS. Notes: Each dot represents the average effective tax rates faced by each age group. See Figure 4 for details. 
Figure 13. Average effective property tax rates for 1989-1990 movers by age, Texas 1990.

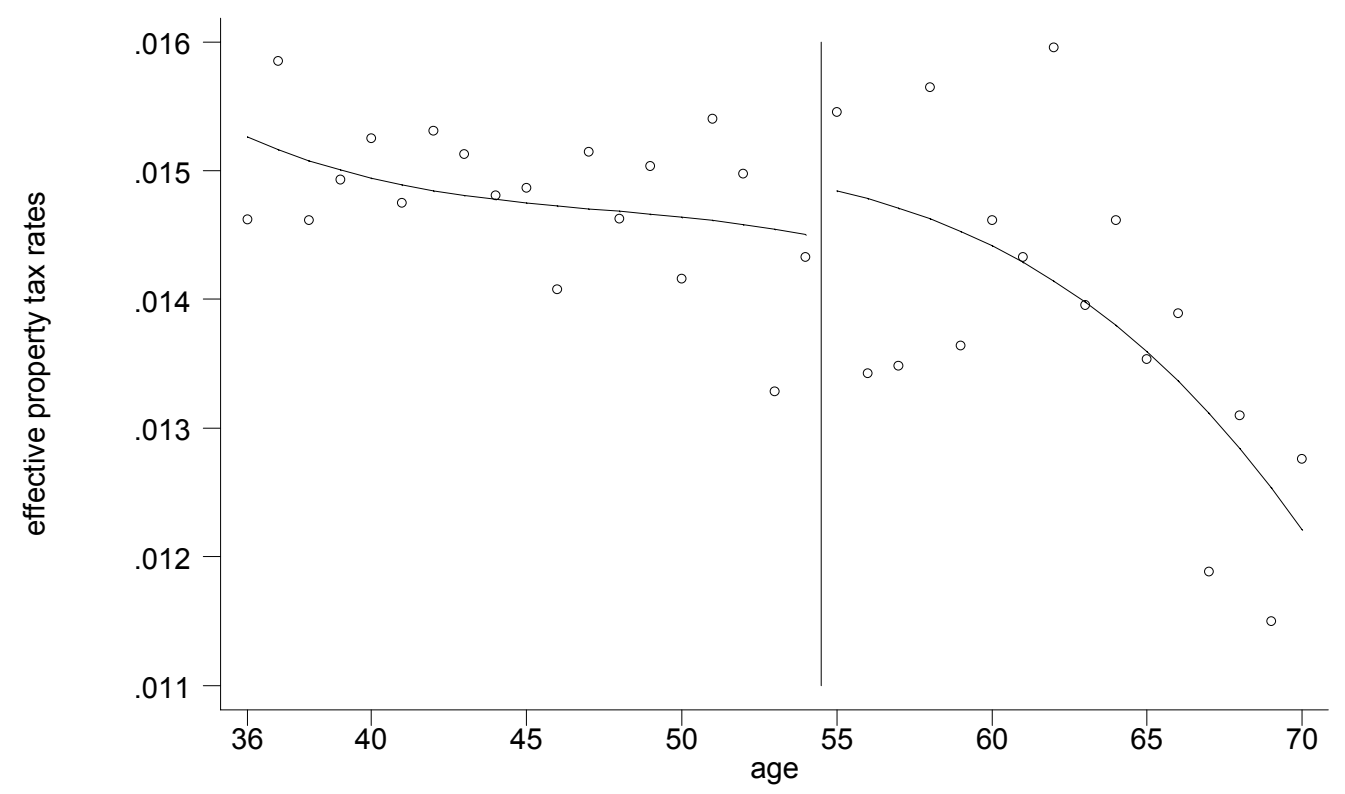

Source: 1990 IPUMS. Notes: Each dot represents the average effective tax rates faced by each age group. See Figure 4 for details.

Figure 14. Probability of moving by ability to transfer the tax benefit for homeowners by age, California 1990.

o allowed to transfer the tax benefit $\quad+$ not allowed

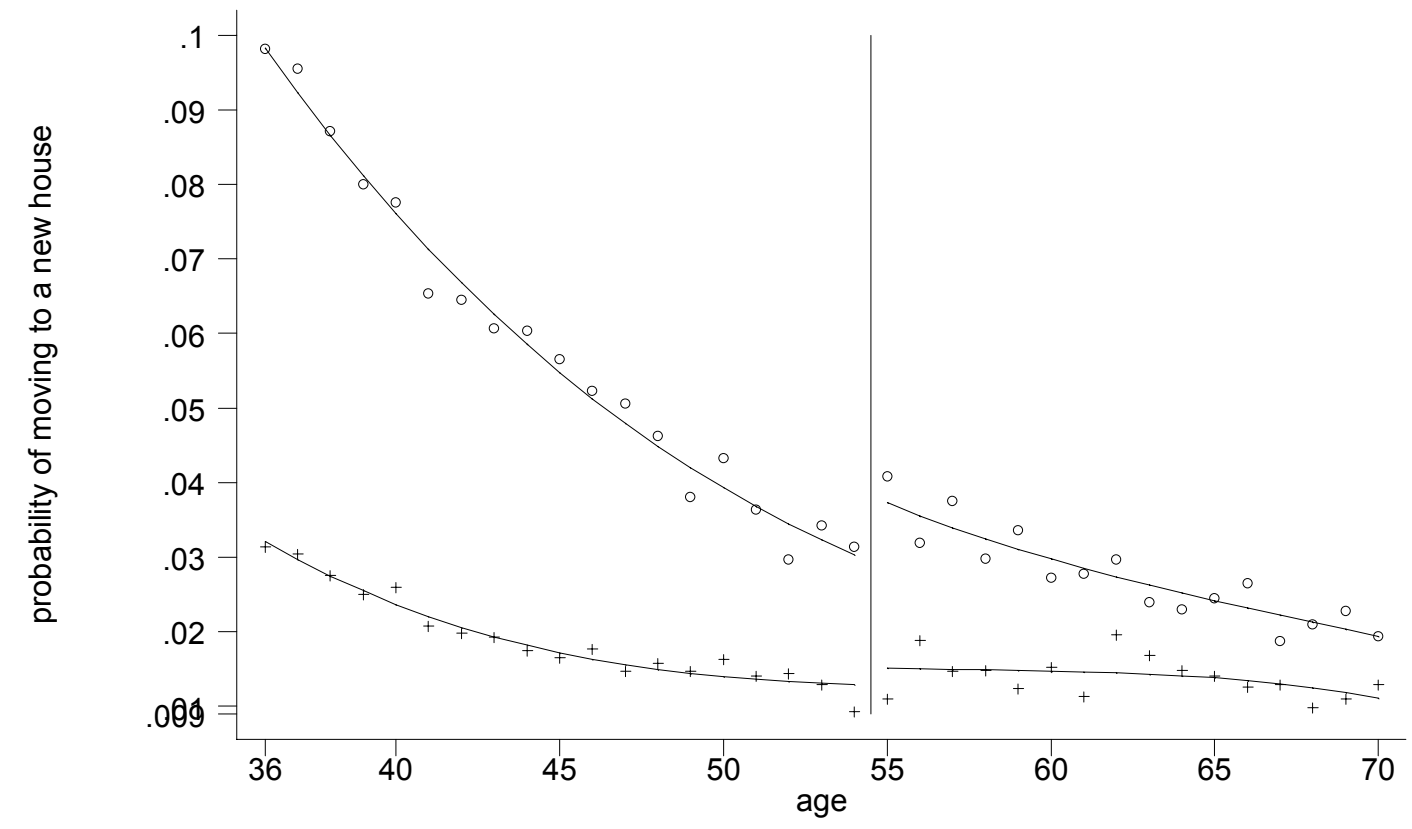

Source: 1990 IPUMS. Notes: The group of homeowners allowed to transfer the tax benefit moved in 1989-1990 within the same county, or to a county without Proposition 90. The remaining homeowners that moved in 1989-1990 were not allowed to transfer the tax benefit. See Figure 4 for details. 
Figure 15. Average property taxes for 1989-1990 movers allowed to transfer the tax benefit by age, California 1990.

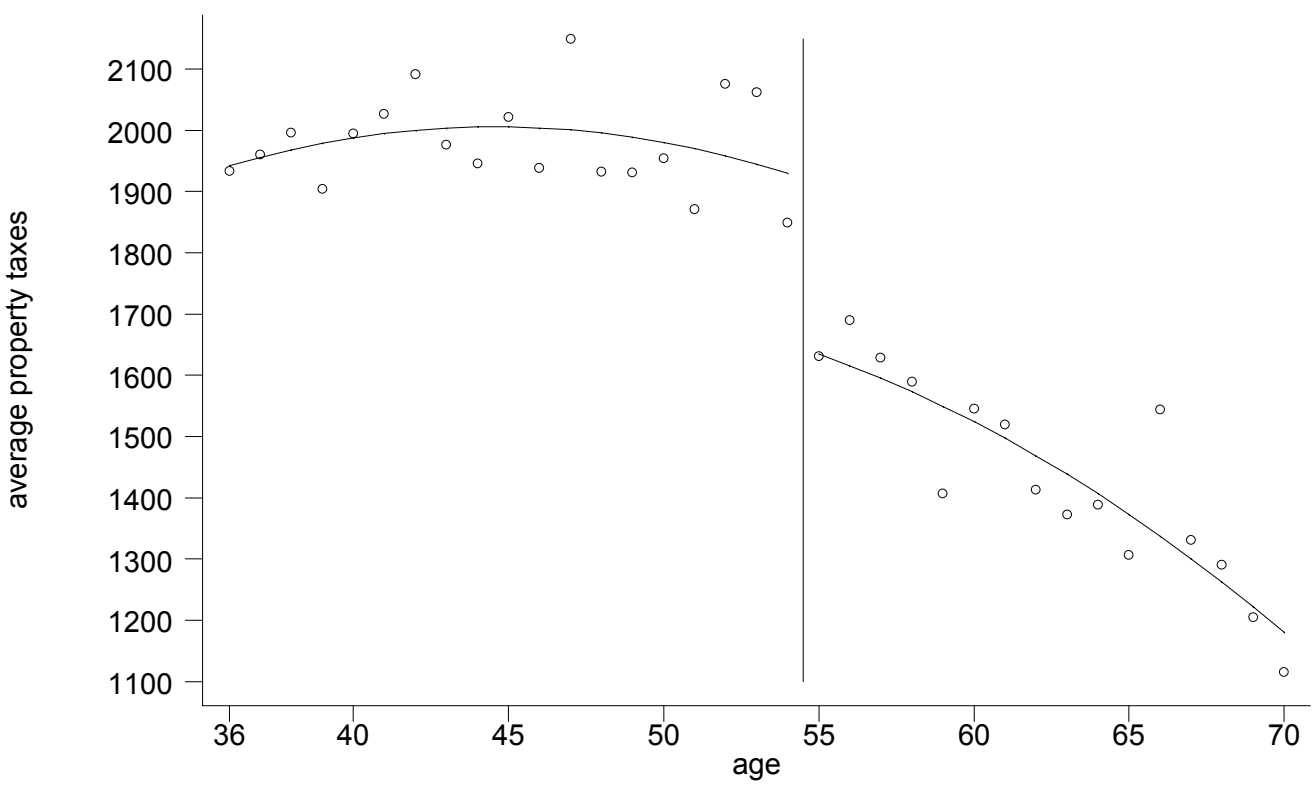

Source: 1990 IPUMS. Notes: Each dot represents the average property taxes faced by each age group. See Figure 4 for details.

Figure 16. Predicted probabilities of moving by age, San Francisco Bay Area 1990

o control function model + simple logit model

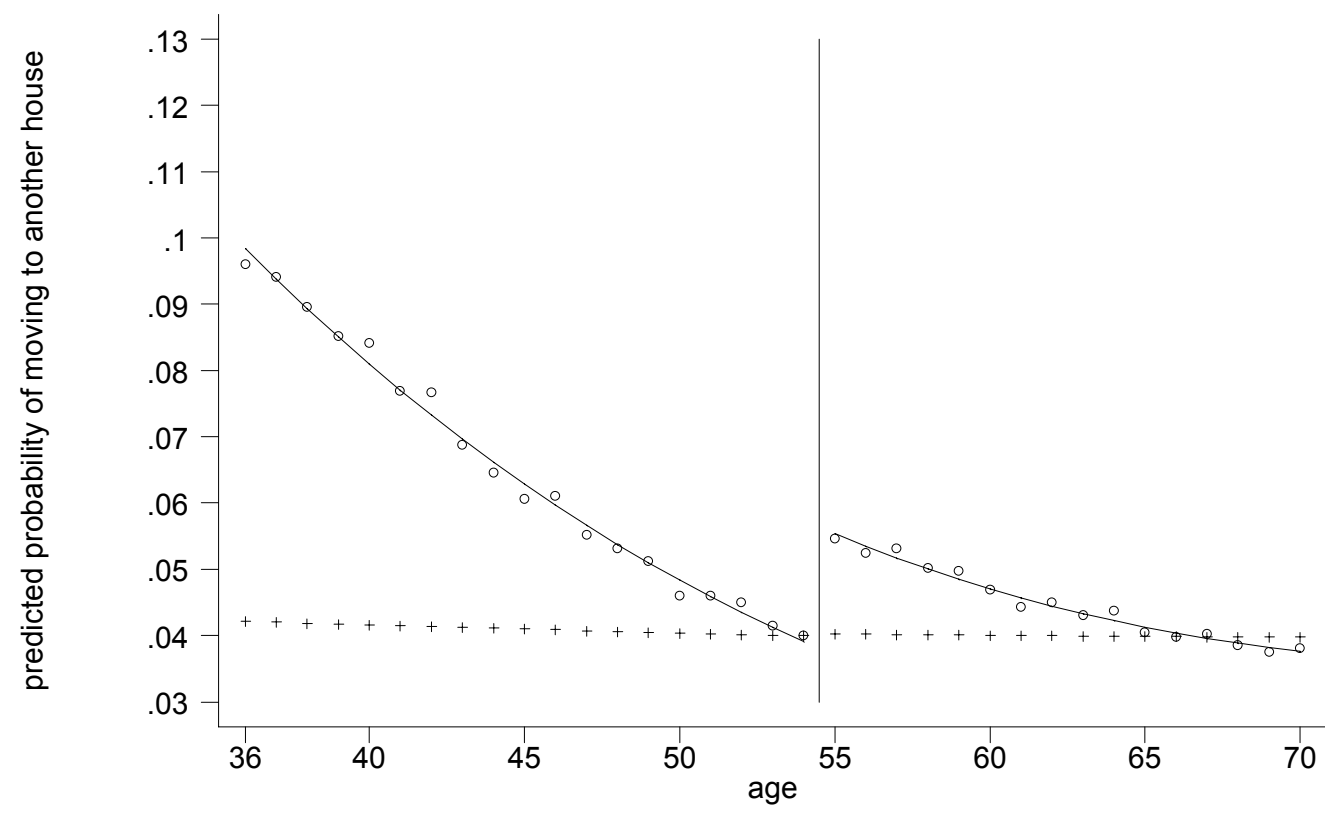

Source: 1990 IPUMS. Notes: The predicted probabilities are normalized by the observed mobility rates of 54-year old homeowners, in order to make the predictions comparable to the results showed in Figure 4. The control function model includes all choice variables and heterogeneity. Results from this figure will be shown for the restricted Census data only after disclosure analysis made by the Census Bureau. 


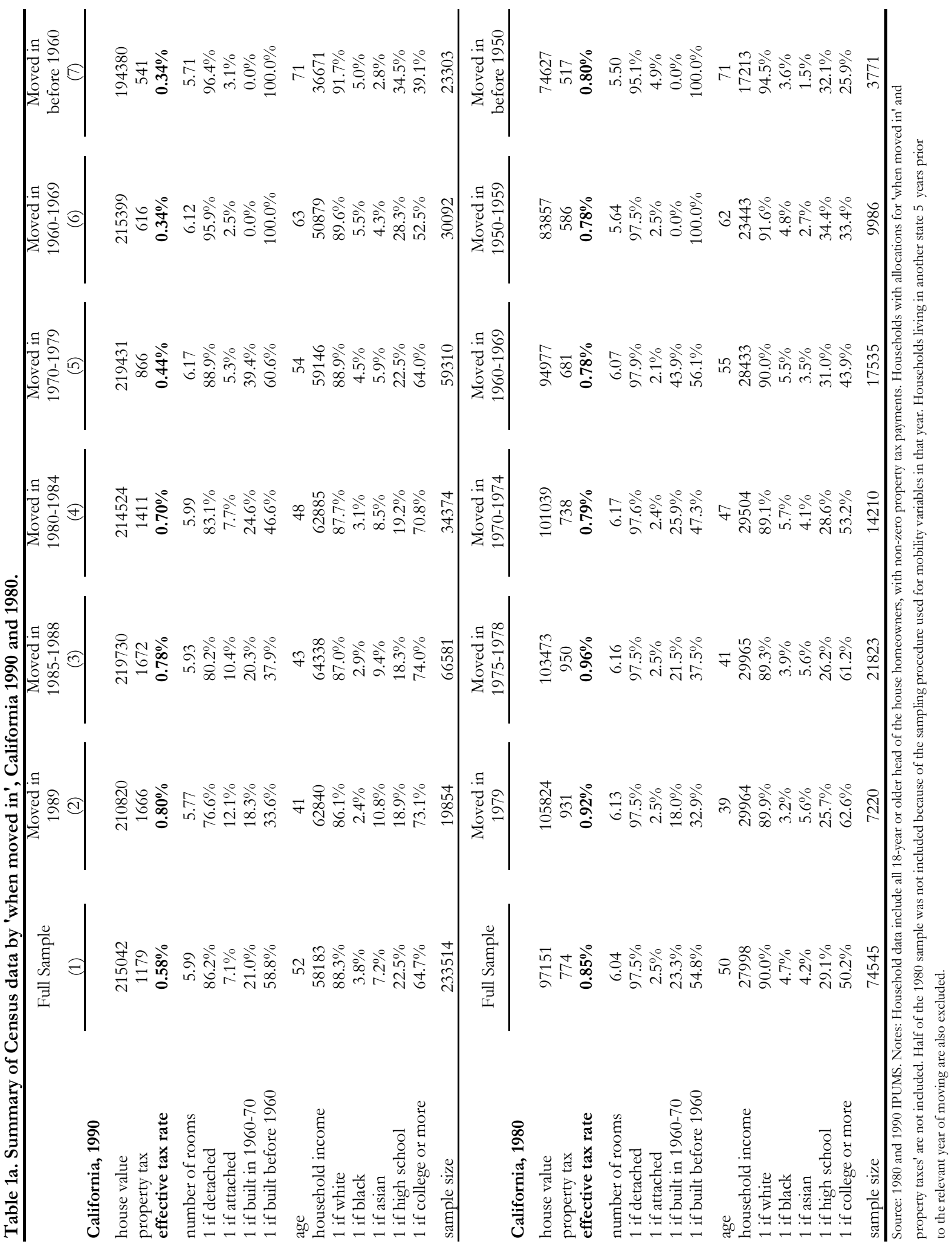




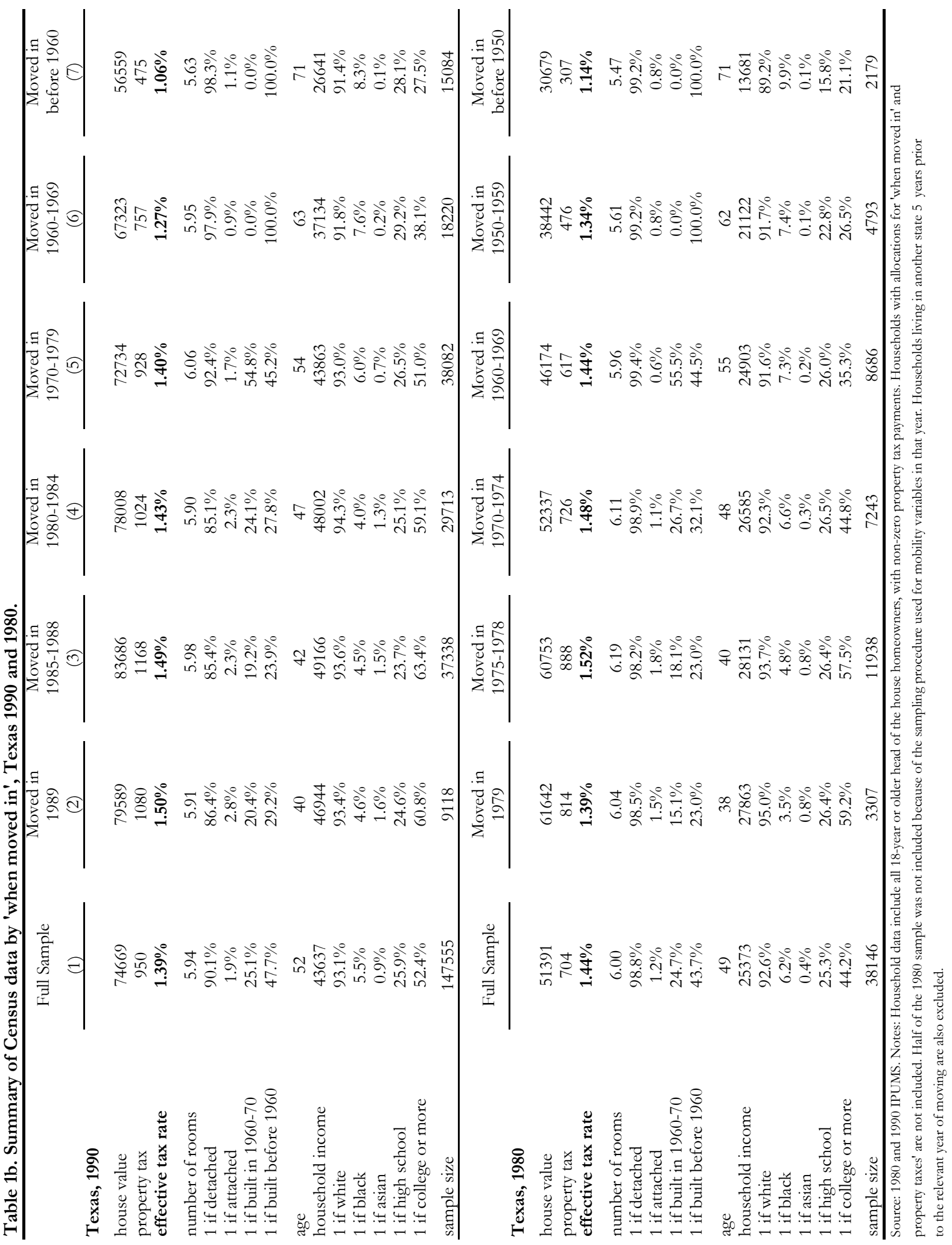




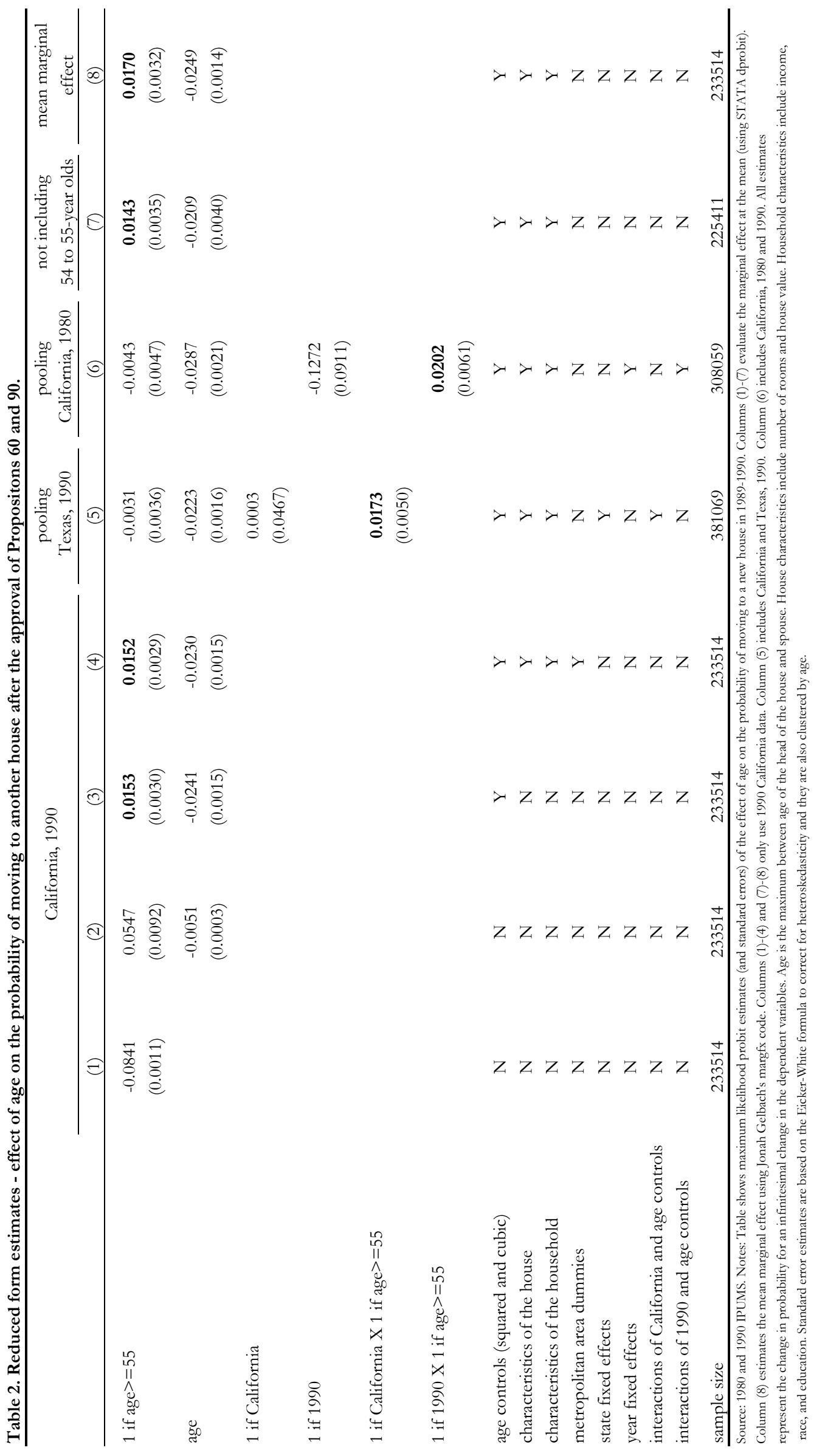




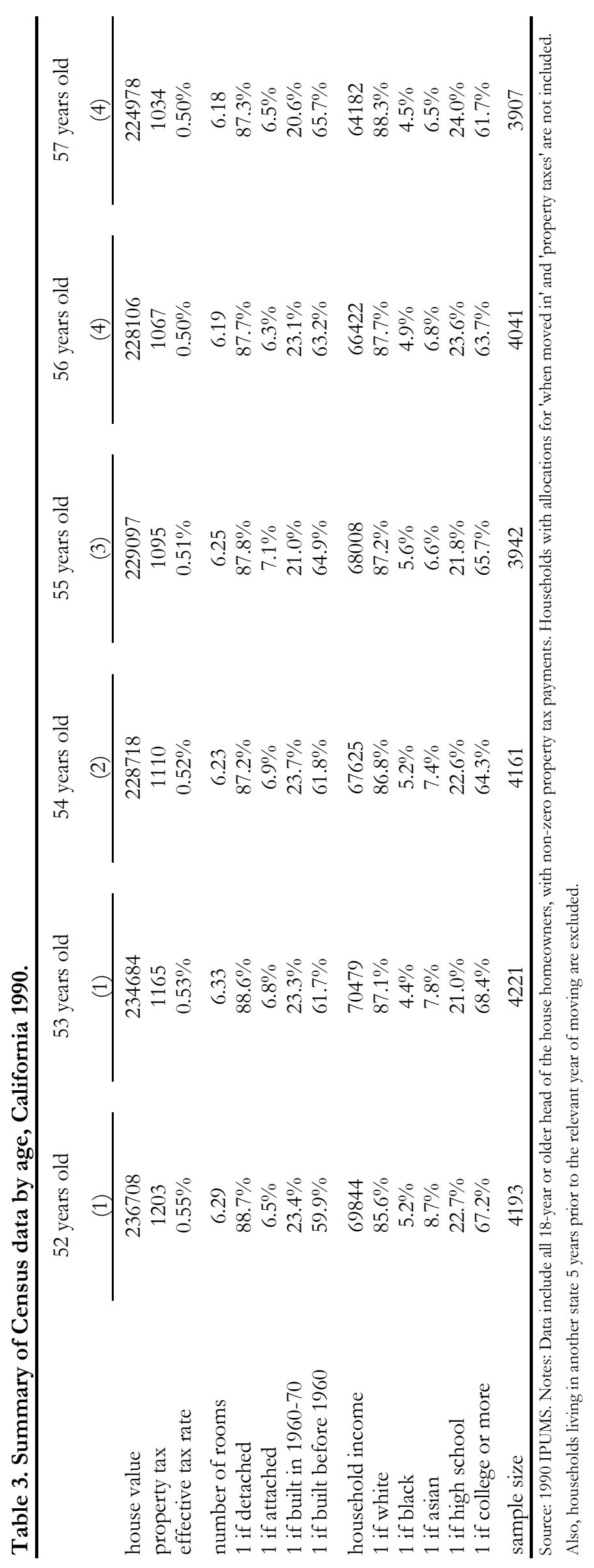




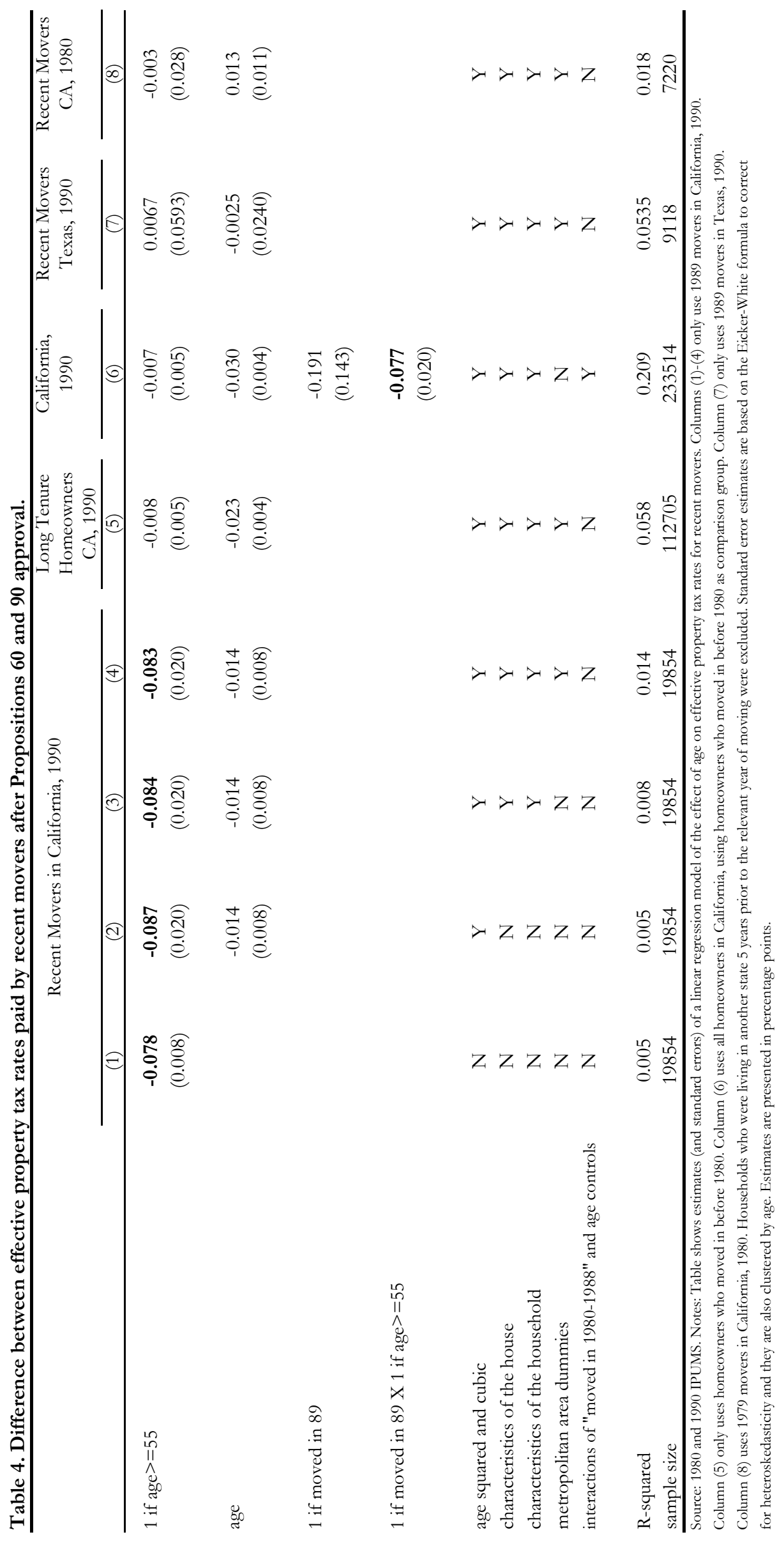




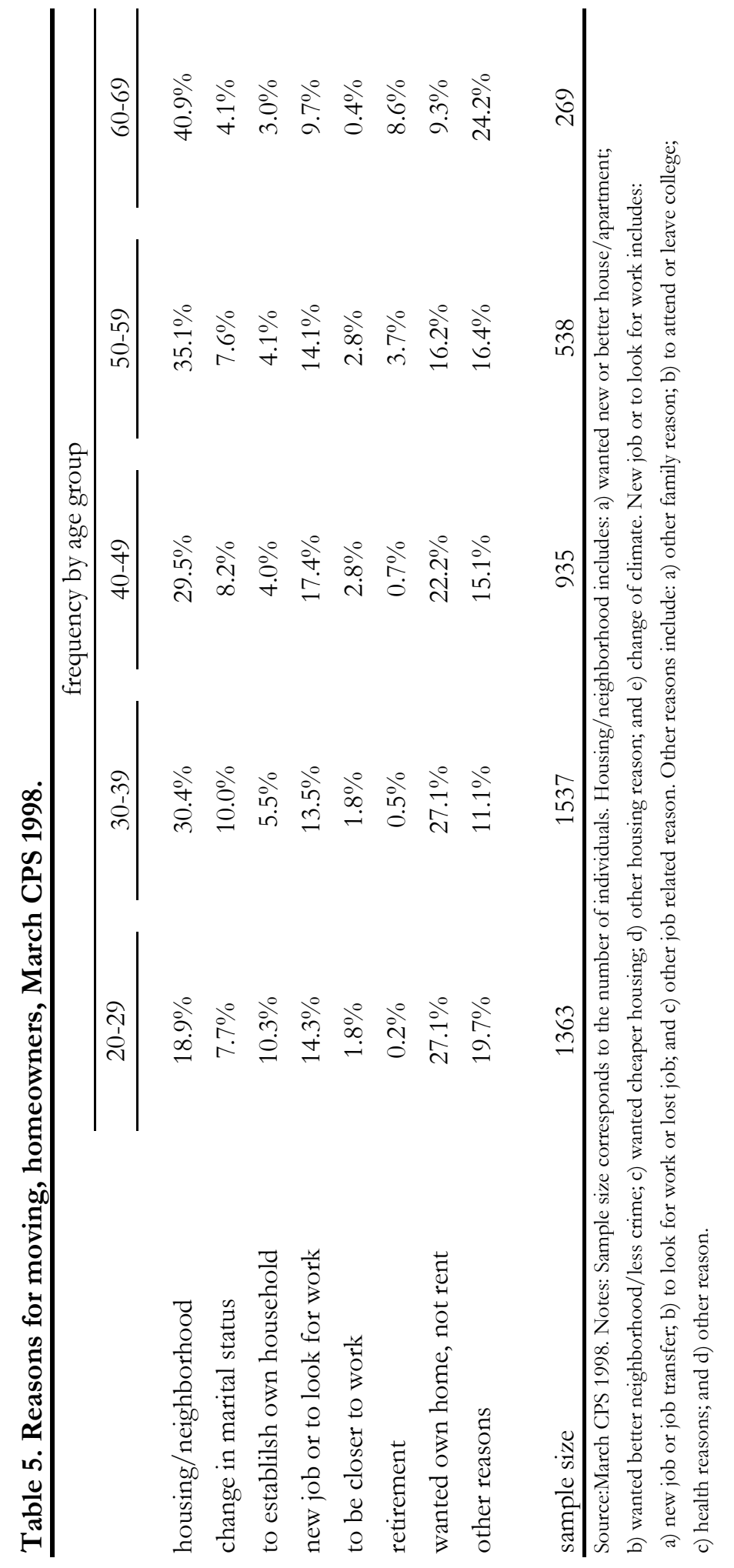


Table 6. Multinomial logit sample, San Francisco Bay Area 1990.

\begin{tabular}{|c|c|c|}
\hline & $\begin{array}{l}30 \text { to } 70 \text {-year old } \\
\text { homeowners } \\
\text { (1) }\end{array}$ & $\begin{array}{c}\text { choice set } \\
(2)\end{array}$ \\
\hline house value & 306984 & 301609 \\
\hline number of rooms & 6.31 & 5.92 \\
\hline 1 if detached & 0.85 & 0.72 \\
\hline 1 if built in 1985-89 & 0.08 & 0.27 \\
\hline 1 if built in $1980-84$ & 0.07 & 0.09 \\
\hline 1 if built in $1970-79$ & 0.20 & 0.20 \\
\hline block group average income & 64546 & 63941 \\
\hline block group $\%$ white & 0.73 & 0.72 \\
\hline elevation & 248.00 & 250.00 \\
\hline 1 st grade test scores & 545.00 & 541.00 \\
\hline population density & 0.28 & 0.27 \\
\hline air quality index & 23.29 & 23.47 \\
\hline sample size & 98407 & 8347 \\
\hline \multicolumn{3}{|c|}{$\begin{array}{l}\text { Source: US Census Bureau - } 1990 \text { California Decennial Census Long Form data and } 1990 \text { IPUMS. Notes: Average income, } \\
\text { percentage white, and density are constructed at the block group level. Elevation is measured at the block level (source: } \\
\text { EPA: BASINS). Test scores are assigned from the closest school within the school district (source: California Department } \\
\text { of Education, 1991-1993). Air quality is predicted for each census block using information from monitor stations (source: }\end{array}$} \\
\hline
\end{tabular}




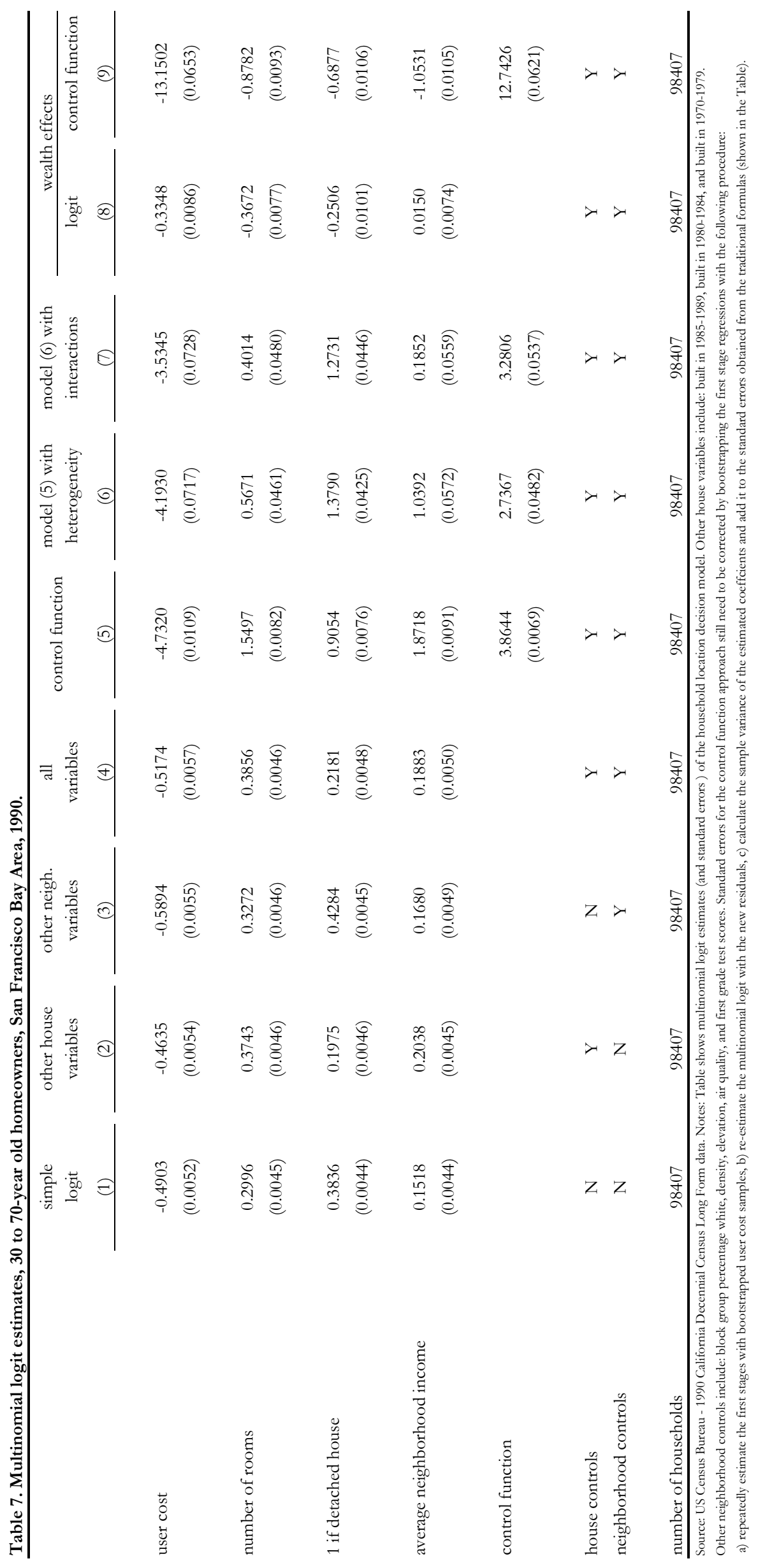




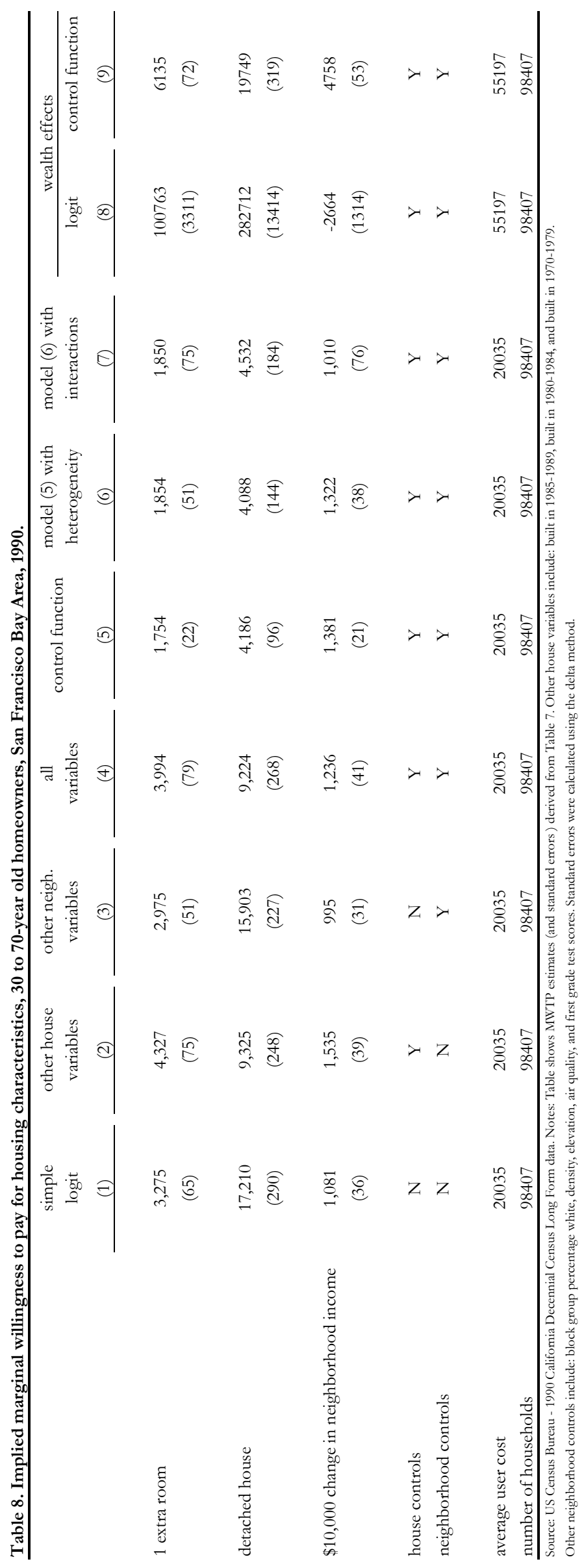




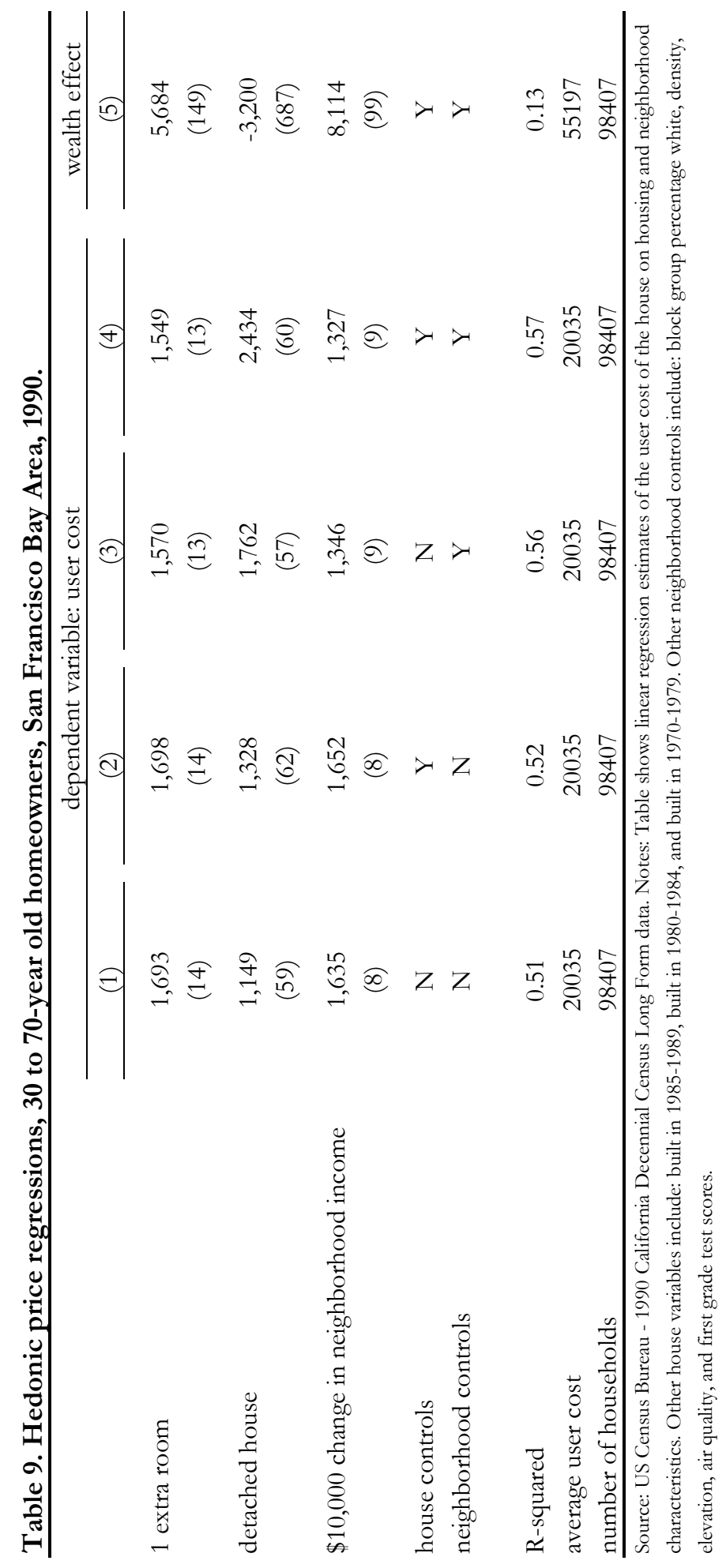




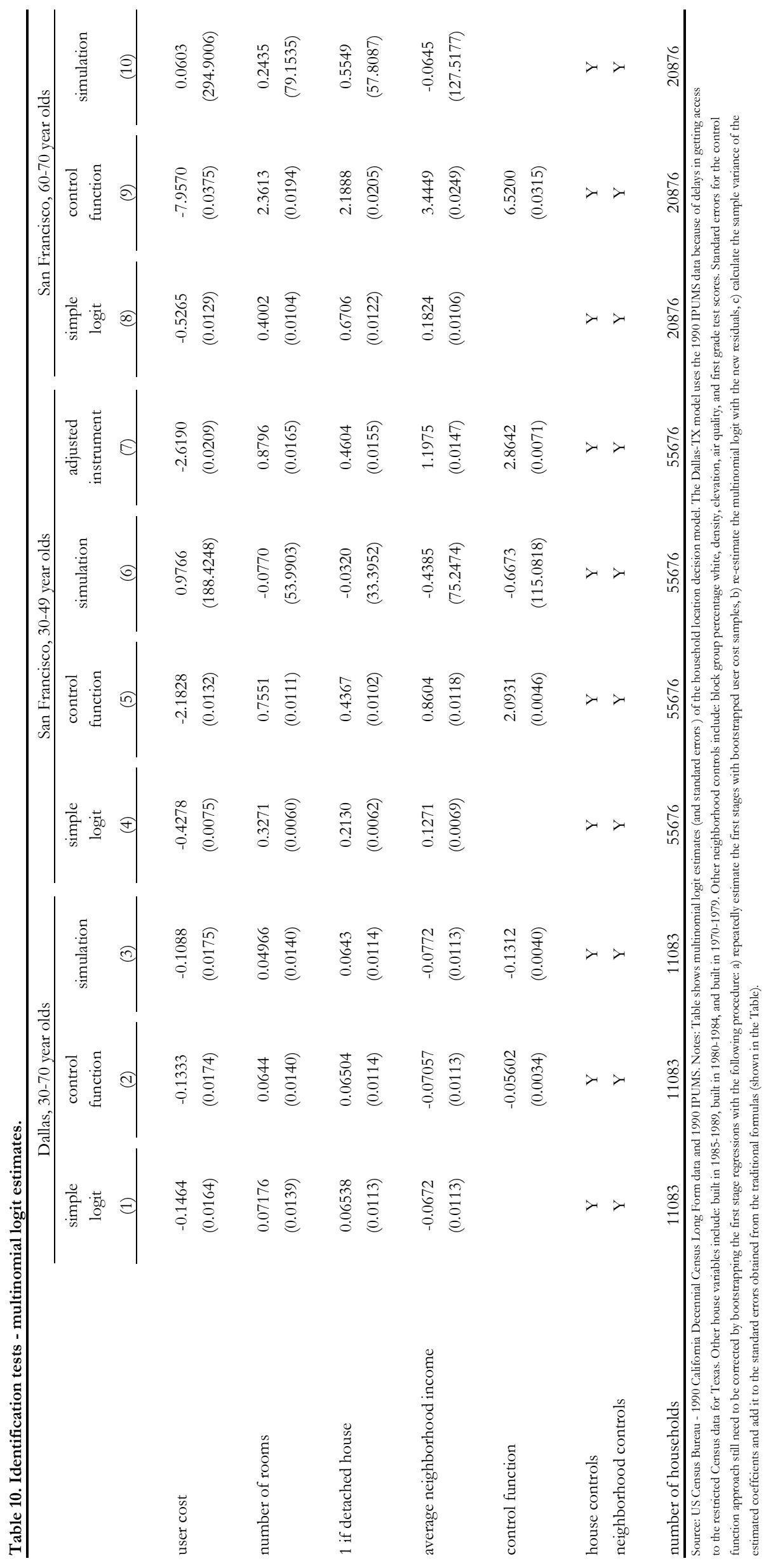




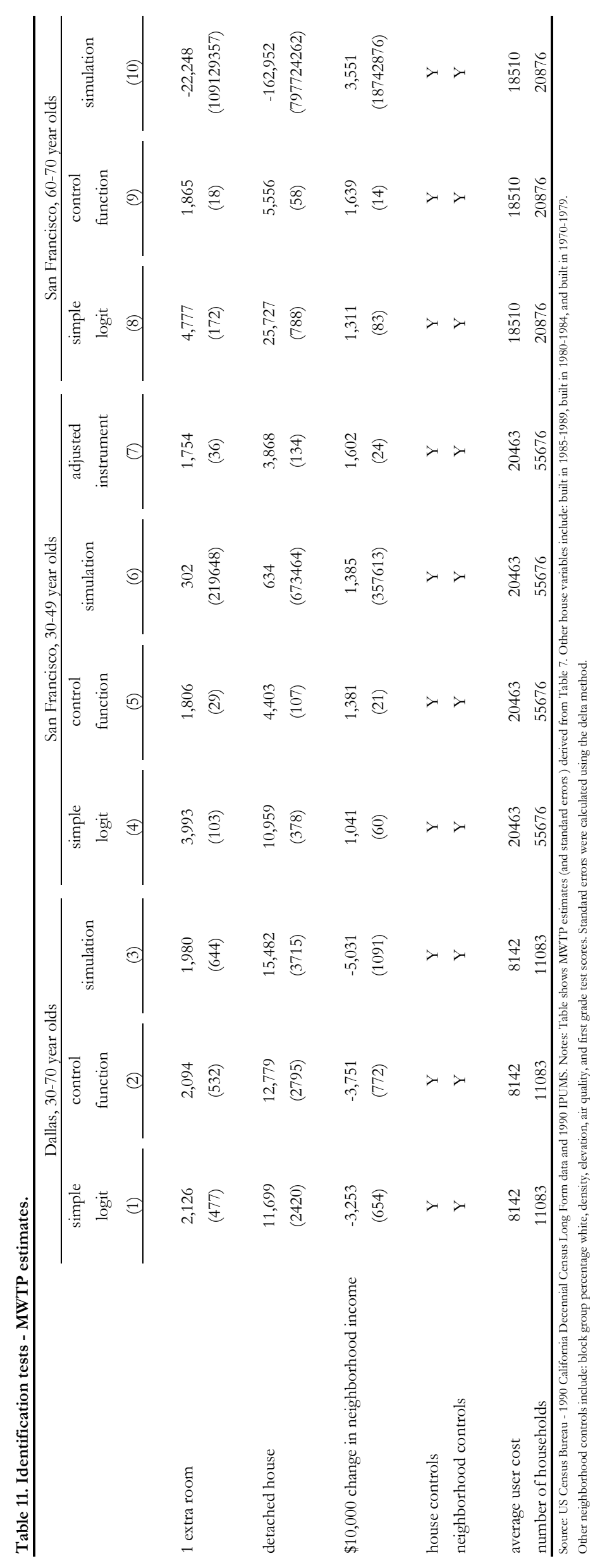




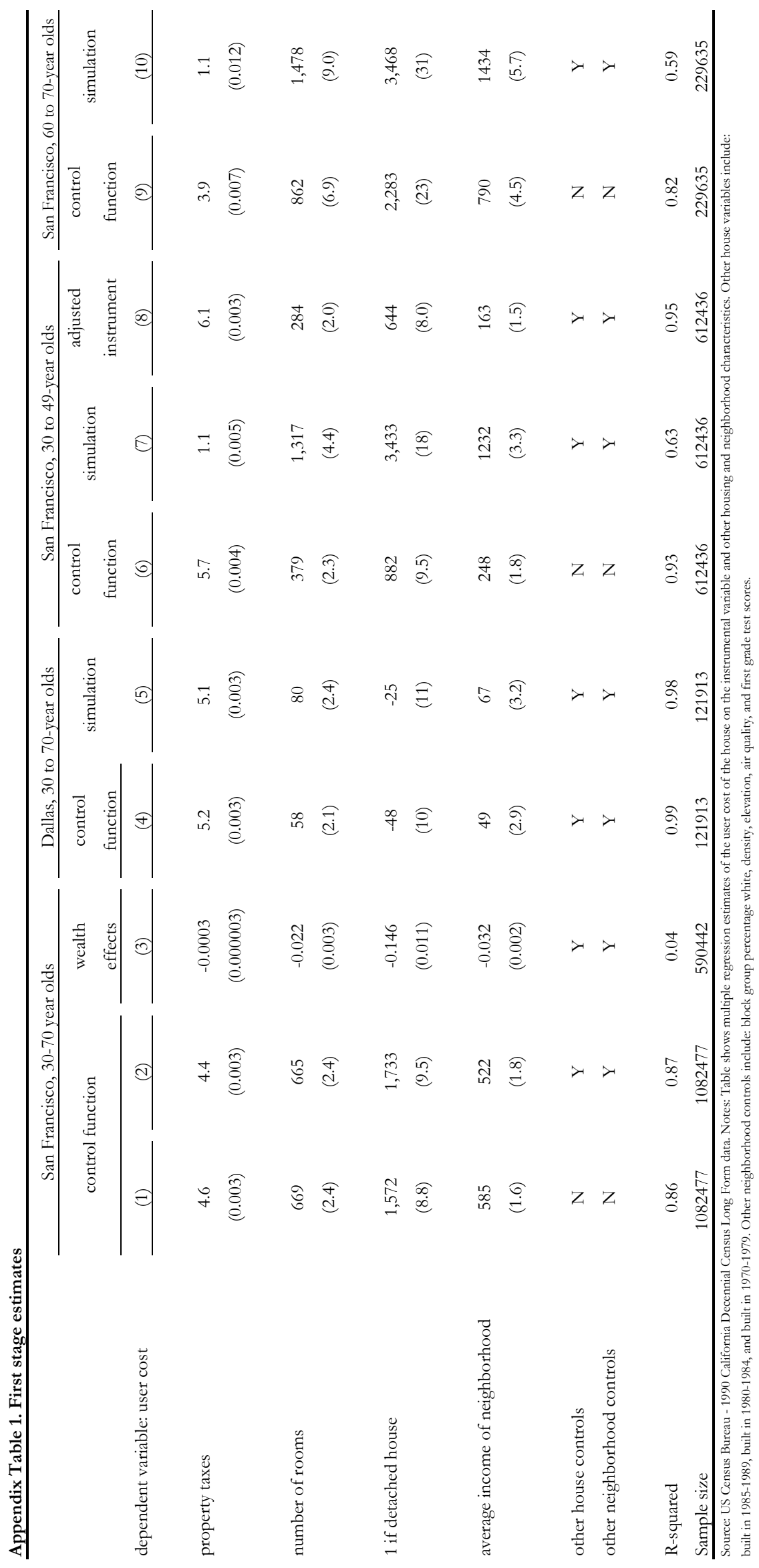

